\title{
A SALINOMICINA COMO ESTIMULANTE DO CRESCIMENTO DE SUINOS EM RECRIA
}

\section{LILA CARLOTA LÖPEZ PRECIADO}

Engenheiro Zootecnista

Orientador: Prof. Dr. VALDOMIRO SHIGUERU MIYADA

Dissertação apresentada à Escola Superior de Agricultura "Luiz de Queiroz", da Universidade de São Paulo, para obtenção do título de Mestre em Agronomia, Area de Concentração: "Nutrição Animal e Pastagens". 
Ficha catalográfica preparada pela Seção de Livros da Divisão de Biblioteca e Documentação - PCAP/USP López Preciado, Lila Carlota

L864s A salinomicina como estimulante do crescimento de suí nos em recria. Piracicaba, 1990.

55p. ilus.

Diss.(Mestre) - ESALQ

Bibliografia

1. Estimulante do crescimento 2. Salinomicina como é timulante do crescimento 3. Suíno - Crescimento - Efeito da salinomicina I. Escola Superior de Agricultura "Luiz de Queiroz", Piracicaba

CDD 636.4 


\section{A SALINOMICINA COMO ESTIMULANTE DO CRESCIMENTO DE SUTNOS EM RECRIA}

Autora: Li la Carlota Lõpez Preciado

Aprovada em: 21.12 .1990

Comíssão Julgadora:
Prof. Dr. Valdomiro S. Miyada
ESALQ/USP
Prof. Dr. Abel Lavorenti
ESALQ/USP
Dr. Gustavo J.M. Monteiro de Lima
EMBRAPA-SC

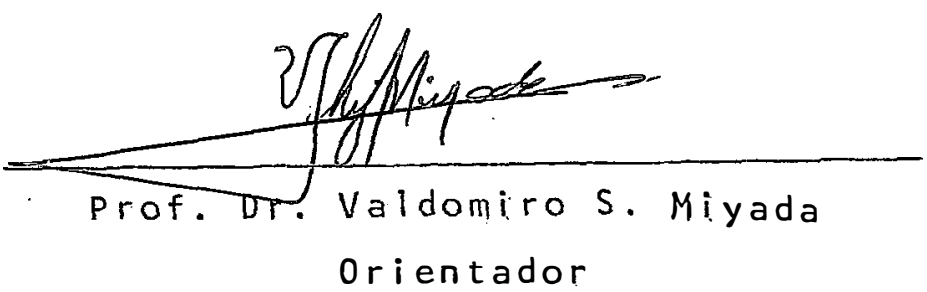


iii.

DEDICO

Ao meu pai Fernān in memorian

A minha mãe Magdalena

Aos meus irmäos Ana, Teresa, e Galo

pelo amor, pelo apoio, pela união. 
iv.

\section{AGRADECIMENTOS}

Ao Prof. Dr. VALDOMIRO SHIGUERU MIYADA, pela constante or entação, valiosas sugestões, apoio e amizade;

Um agradecimento especial ao Prof. Dr. ABEL LAVORENTI, pela amizade e por ter feito possivel o curso de pós-graduação e a orientação inicial deste.

As amigas JACINTA DIVA GOMES FERRUGEM e ROSĀNGELA M. POSSOBON, pela grande ajuda na condução do experimento;

Aos funcionārios do Setor de Suinocultura do Departamento de Zootecnia, da ESALQ, pela colaboração prestada;

Aos amigos que colaboraram de uma ou outra forma na realiza ção deste trabalho. 


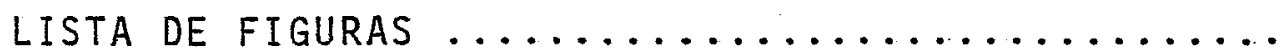

vi i

LISTA DE TABELAS $\ldots \ldots \ldots \ldots \ldots \ldots \ldots \ldots \ldots \ldots \ldots$

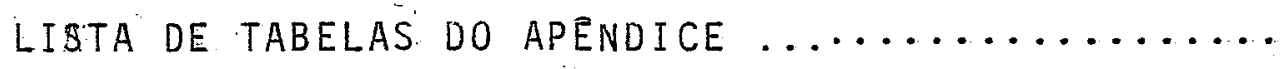

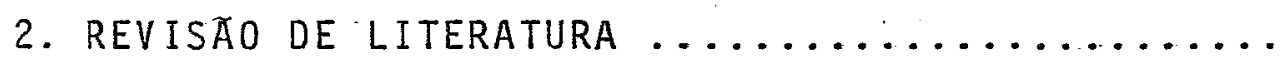

2.1. Os antibióticos e o seu efeito promotor do

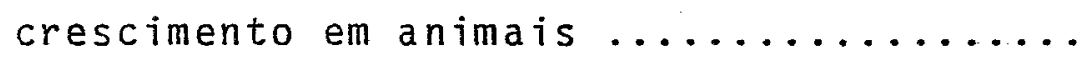

2.2. Modo de ação dos antibióticos ianoforos...

2.3. Os ionoforos e a fisiologia do hospedeiro.

2.4. A salinomicina e outros ionoforos: sua aplicação nas diferentes espēcies animais.

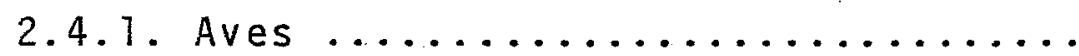

2.4.2. Ruminantes $\ldots \ldots \ldots \ldots \ldots \ldots \ldots$

3. MATERIAL E MEtodos $\ldots \ldots \ldots \ldots \ldots \ldots \ldots \ldots \ldots \ldots . \ldots \ldots$

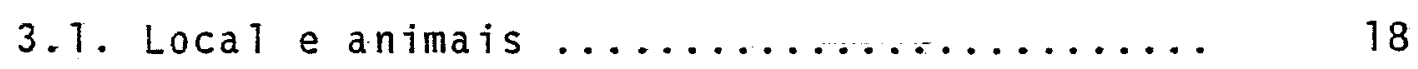

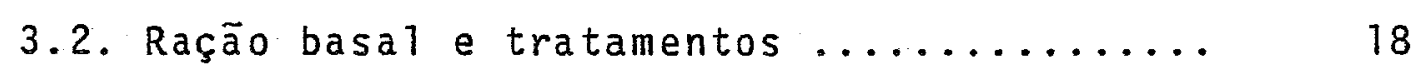

3.3. Manejo e colheita de dados ............. 19

3.4. Anāilise estatistica .................. 23

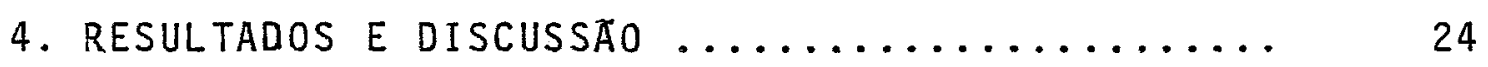

4.1. Caracteristicas de performance .......... 24

4.2. Componentes sanguíneos e plasmáticos .... 30

5. CONCLUSÖES $\ldots \ldots \ldots \ldots \ldots \ldots \ldots \ldots \ldots \ldots \ldots \ldots \ldots \ldots \ldots$ 
$v i$.

Pāgina

REFERENCIAS BIBLIOGRAFICAS $\ldots \ldots \ldots \ldots \ldots \ldots \ldots \ldots$

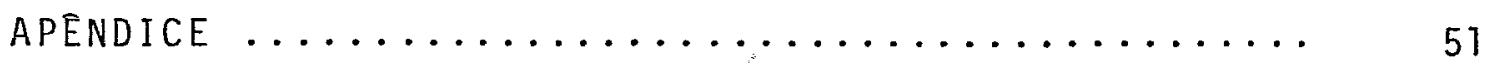


vii.

\section{LISTA DE FIGURAS}

FIGURA NỌ

Pāgina

1

Efeito dos niveis de salinomicina sobre o ganho diārio de peso e consu-

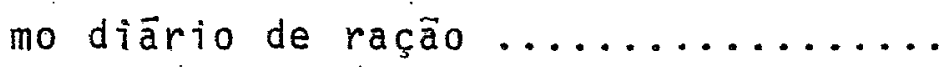

Efeito dos niveis de salinomicina so-

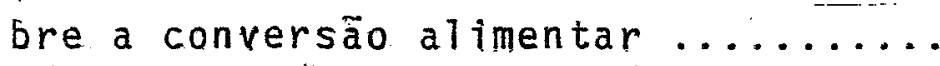

Efeito dos niveis de salinomicina sobre os trigliceridios do plasma .... 
TABELA No

Pāgina

1

Produtos utilizados como promotores do crescimento em suinos, nas diferentes

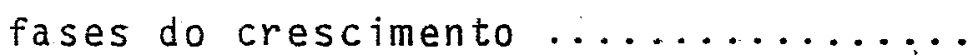

2

Composição quîmica e energia digestï-

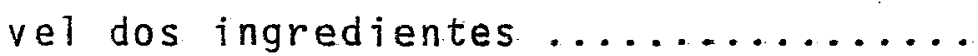

4

Médias das caracteristicas de performance dos suinos em recria, alimenta dos com rações contendo niveis crescen

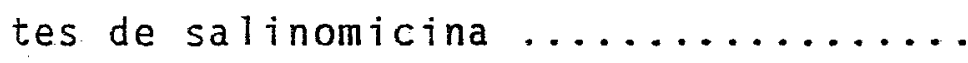

Médias dos componentes sanguineos e plasmāticos dos suinos em recria, al $\underline{i}$ mentados com rações contendo nīveis crescentes de salinomicina .......... 


\section{LISTA DE TABELAS DO APENDICE}

TABELA NO

Pãgina

A 1

Peso mêdio inicial (PMI, $\mathrm{kg}$ ), peso mēdio final (PMF, $\mathrm{kg} L$, consumo diārio de ração (CDR, kgl, ganho diārio de peso (GDP, kg) e conversão a imentar (CA) dos animais.

A2

Componentes sanguineos (hematócrito e he moglobina) e plasmāticos (urēia, proteína tota 1, albumina, globulina, relaçāo albumina/globulina e trigliceridios) ... 


\title{
A SALINONICINA COMO ESTIMULANTE DO CRESCIMENTO DE SUINOS EM RECRIA
}

\author{
Autor: LILA CARLOTA LOPEZ PRECIADO \\ orientador: Prof. Dr. VALDOMIRO SHIGUERU MIYADA
}

\section{RESUMO}

Um experimento, envolvendo 85 leitões mestiços (Landrace $x$ Large White $x$ Duroc) com peso mëdio inicial 10,77 $\mathrm{kg}$ e peso médio final $24,39 \mathrm{~kg}$, foi conduzido durante um periodo experimental de 28 dias, com o objetivo de avaliar o antibiōtico ionoforo salinomicina como promotor do crescimento dọs animais. Assim, nỉveis dietéticos de $0,25,50,75 \mathrm{e}$ $100 \mathrm{ppm}$ foram incorporados a uma ração basal (18\% PB e 3.386 $\mathrm{kcal} E D / \mathrm{kgl}$ de milho, farelo de soja, sacarose e suplementos minerais e vitaminicos. Os animais foram alojados em gaiolas metāificas suspensas de $1,50 \times 1,20 \mathrm{~m}$, com āgua e ração à vontade. As pesagens individuais dos leitôes e a coleta dos dados de consumo de ração/parcela foram semanais. 0 delinea mento experimental foi 0 de blocos casualizados, com 8 repetịçôes/tratamento e com 2 ou 3 animais/unidade experimental. as niveis dietéticos de salinomicina proporcionaram uma resposta linear $(P<0,02 L$ e quadrätica $(P<0,03)$ do consumo dia rio de ração (CDR; $0,297_{2} .1,060,1,018,0,984$ e $0,905 \mathrm{~kg}$ ), as sim como uma resposta quadrātica $(\rho<0,01)$ do ganho diārio 
de peso (GDP; $0,488,0,533,0,533,0,517$ e $0,479 \mathrm{kgl}$ e uma meThora linear $(P<Q, 02 L$ da conversão alimentar $(C A ; 2,071$, $1,999,1,929, \mathrm{~T}, 910$ e 1,9032 . Tais respostas puderam ser descritas pelas equaçöes: $\operatorname{CDR}=1,000339+0,002282 x-0,000032 x^{2}$; $G D P=0,49039+0,00195 x-0,00002 x^{2}$ e $C A=2,04750-0,00105 x$. Quanto aos parāmetros sanguīneos e plasmáticos, o hematōcrito $(34,4 T, 34,71,35,25,33,88$ e $32,94 \%)$, a hemoglobina $(10,78$, $11,10,17,14,10,86$ e $10,65 \mathrm{~g} / \mathrm{dT}$ l, a urēia $(28,75,27,25,30,13$, 28,38 e $27,38 \mathrm{mg} / \mathrm{d} 1$ L, a proteina total $(5,88,5,88,5,90,5,91$ e $5,74 \mathrm{~g} / \mathrm{dl} \mathrm{L}$, a a.bumina $(3,09,3,23,3,23,3,19$ e: $3,16 \mathrm{~g} / \mathrm{dl})$, a globulina $(2,29,2,65,2,66,2,74$ e $2,58 \mathrm{~g} / \mathrm{d} 1)$ e a relação a Eumina/globulina. $(1,18,1,26,1,23,1,22$ e 1,28) não sofreram a influência $(P>0,05)$ dos nîveis de salinomicina na ração. Por outro lado, este antibiótico apresentou um efeito $1 \underline{\mathfrak{i}}$ near $(P<0,008 I$ depressivo no conteúdo plasmático de triglice rî̀íos (TGL com mëdias de $65,38,58,50,52,25,59,50$ e 50,38 mg/dT respectivamente, e representado pela equação: TG $=63,000$ - 0,116x. Os resultados deste experimento evidenciam o efeito da salinomicina como estimulante do crescimento de suinos em recria. E embora haja indicações de uma melhora continua na conversão alimentar, o maior ganho de peso foi alcançado com cerca de $50 \mathrm{ppm}$ do antibiôtico na ração. 


\title{
SALINOMYCIN AS A GROWTH PROMOTOR OF WEANLING PIGS
}

\author{
Author: LILA CARLOTA LOPPEZ PRECIADO \\ Adviser: Prof. Dr. VALDOMIRO SHIGUERU MIYADA.
}

\section{SUMMARY}

An experiment, involving 85 crossbred weanlins pigs (Landrace $x$ Large White $x$ Duroc), was carried out to evaluate the effect of salinomycin, a ionophorus polyeter antibiotic, as a growth promotor of baby pigs. Thus, levels of $0,25,50,75$ and 700 ppm of salinomycin, were added to a corn-soybeanmeal sucrose basal diet with $18 \%$ CP, 3.386 kcal $D E / k g$ and supplemented with minerals and vitamins. A complete block design with 8 replicates/treatment and 2 or 3 pigs/experimental unit was used. Water and diets were given "ad libitum:" Weekly, the pigs were weighed individualy and the data of feed intake/pen was registered. Salinomycin had a linear $(P<0,02)$ and quadratic $(P<0.03)$ effect on daily feed intake (DFI, $0.291,1.060,1.018,0.984$ and $0.905 \mathrm{~kg}$, a quadratic effect $(P<0.012$ on average daily gain $(A D G, 0.488$, $0,533,0,533,0,577$ and $0,479 \mathrm{~kg})$ and a linear effect $(P<0.02 L$ on feed conversion ( $F C ; 2.071,1.292,1.229,1.910$ and 1.203$)$. Such effects could be described by the following equations: DFI = 
$1,000339+0,002282 x-0,000032 x^{2}, A D G=0,49039+0,00195 x-$ $0,00002 x^{2}$ and $F C=2.04750-0,00105 x$. Concerning to the blood and plasma parameters, hematocrit $(34.41,34.71,35.25$, 33.88 and $32.94 \%$ ), hemog 70 in $(10.78,11.10,11.14,10.86$ and $10.65 \mathrm{~g} / \mathrm{dTL}$, urea $(28.75,27.25,30.13,28.38$ and $27.38 \mathrm{mg} /$ dI), total protein $(5.88,5.88,5.90,5.91$ and $5.74 \mathrm{~g} / \mathrm{d} 1)$, a 1 bumin $(3.09,3.23,3.23,3.19$ and $3.16 \mathrm{~g} / \mathrm{d}])$, globulin $(2.79$, $2.65,2.66,2.74$ and $2.58 \mathrm{~g} / \mathrm{d} 1)$ and albumin/globulin ratio $(1.18,1.26,1.23,1.22$ and 1.28$)$ were not affected $(P>0.05)$ by the added salinomycin to the diet. On the other hand, this antibiotic showed a depressive linear $(P<0.008)$ effect on plasma trigliceride content (TG, 65.38, 58.50,52.25, 59,50 and $50.38 \mathrm{mg} / \mathrm{dl} 1 \mathrm{~L}$ as described by the equation $T G=63,000-$ $0.116 \dot{x}$. The results of this experiment showed the effect of salinomycin as a growth promotor of weanling pigs. As such, $50 \mathrm{ppm}$ of ionophorus in weanling pig diet showed to be the best level for weight gain, al though the feed conversion was improved up to $100 \mathrm{ppm}$. 


\section{INTRODUCÃO}

A utilização de antibiōticos, como aditivos de raçöes animais, é uma prātica comumente utilizada pelos produtores, tanto de rações como de premixes. Assim, nos ü timos anos, muitos pesquisadores têm dado ênfase aos estudos sobre o uso destes aditivos que possuem a capacidade de promover o crescimento dos animais. Dentre eles podemise, desta car os estudos envolvendo os antibióticos ionoforos.

Algumas pesquisas mostram que estes antibioticos são capazes de aumentar a absorção de nitrogēnio no in testino delgado, assim como a digestibilidade da fibra e da energia em suínos. Hā indicações que eles exercem um efeito direto sobre o metabolismo microbiano no trato gastro-intestinal destes animais.

A salinomicina $\bar{e}$ um ionoforo carboxilico poliëter, produzido por cepas de Streptomices albus (Kinashi et al $i^{1}$, citados por UHEELHOUSE \& GROVES, 1985), que possui a tividade con

7 KINASHI, H.; OTAKE, N. \& YONEHARA, H. The structure of Salinomycin a new member of the polyether antibiotic. Tetrahedron Lett., 49: 4958, 1975 . 
tra bactērias gram positivas e coccidias.: Ela tem sido ut lizada como um eficiente coccidiostático em frangos de corte e como promotor do crescimento de animais ruminantes. Hä in dicações tambēm de que este ionoforo pode ser um promotor de crescimento de îleitōes em recria e de suĩnos em crescimentoacabamento.

No entanto, fatores como a idade dos animais, condiçôes sanitārias e climāticas, composição das rações, nị veis do antibiötico na raçäo, etc., podem influenciar a resposta dos animais aos diversos aditivos. Portanto, $\bar{e}$ de extrema importāncia a realização de estudos, para estabelecer o nîvel dietético de salinomicina como promotor do crescimento dos suinos.

Assim, o presente experimento teve como objetivo fazer um estudo dos efeitos de diferentes nīveis de salinomicina em rações de suīnos em recria sobre a performance dos animais. Alēm disso, foram também avaliados os efeitos deste antibiōtico sobre importantes componentes sangu프 neos (hematōcrito e hemoglobina) e plasmāticos (urēia, proteīna total, albumina, globulina, relação albumina/globulina e $\operatorname{trig} 7$ icer $\bar{i}$ dios). 


\section{REVISÃO DE LITERATURA}

\subsection{Os antibióticos e o seu efeito promotor do crescimento em animais}

Os estudos sobre a utilização de antibióticos, co mo promotores de crescimento em animais, vêm sendo desenvolvi dos há cerca de 40-45 anos. MOQRE et ali i (1946) foramos prí meiros pesquisadores que relataram a possibilidade de certos produtos, como o succinil sulfatiazol e a estreptomicina, terem a capacídade não só de controlar certas infecções, como também proporcionarem um aumento de até $30 \%$ no crescimento de frangos. Assims. outros pesquisadores começaram a estudar substāncias coc ciostáticas, como a clortetraciclina (HARNED et aliil, citados por VISEK, 1978L, amōnia quaternāria (RIEDEL et alii, 1949) e aureomicina (STOKSTAD et alii, 1953; BRAUDE et alii, 1955) e observaram que estes aditivos também promoviam o crescimento de aves e de suínos. A partir destes estudos, houve um rápido cres cimento na utilização dos antibiōticos e quimioterápicos na in dustria animal e, mais especificamente, na de suĩnos.

GARNED, B.K.; CUNNINGHAM, R.W.; CLARK, M.C. COSGROVE, R.; HINE, C.H.; MCCAULEY, W.J.; STOKEY, E.; VESSEY, R.E.; YUDA, N.N.; SUBBAROW, $Y$. The pharmacology of duomycin: Am. N:Y. Acad. Sci., 51: 182, 1948. 
Muitas pesquisas objetivando uma melhora na performance dos suínos, têm sido realizadas, conforme mostra a Tabela 1. A maioria dos aditivos utibizados nas raçöes des tes animais tem proporcionado aumentos no ganho diārio de pe so (8 a 17\%), melhoras na conversão alimentar $(2,9$ a $7,6 \%)$, assim como prevenção da incidência de diarréias e doenças res piratörias em suĩnos de diversas idades.Alēm destas ações, os antibiōticos e quimioterāpicos, geralmente proporcionam uma meThor resposta dos animais a situaçōes de "stress", tais como,..desmama, mudanças de baia, transporte, etc. (CRAVENS \& HOLCK, 1970; LILLIE et a $1 \mathrm{i}$, 1977 e VISEK, 1978).

Tabela 1. Produtos utilizados como promotores do crescimento em suinos, nas diferentes fases do crescimento.

Nome do produto

Autor(es)

Tilosina

0 laquindox

Espiramicina

Carbadox

Lincomicina

Nosiheptide

Bacitracina de Zn

Aureo SP
PACHECO - (1978)

BARBER et alii (1979)

VERVAEKE et a $1 \mathrm{i} i, 1979$ e

CAMPBELL (1982)

YEN \& VEUM (1982)

VELOSO et alii (1982)

CROMWEL et a 1 i $(1984)$

CHOI (1985)

POND \& YEN (1987)

1 Mistura de aureomicina estreptomicina e penicilina. 
Tem sido observado, tambēm, que estes agentes reduzem a utilização microbiana de nutrientes essenciais do trato gastrointestinal. Como consequēncia, hā um aumento na disponibilidade destes nutrientes para o animal, principalmen te a das vitaminas do complexo B (VISEK, 1978). E importante ressaltar ainda que estes agentes proporcionaram uma dim $\underline{j}$ nuição na população microbiana do trato intestinal e, como consequēncia, a redução na produção de amônia. Desta forma, a ação tōxica da amōnia sobre o epitēlio intestinal é diminuída, per mitindo um aumento na absorção dos nutrientes (VISEK, 1978).

Há evidēncias também, de que o uso de antibiōticos diminui a concentração de amōnia no sangue portal, assim como a hidrōlise dos àcidos biliares e a da uréia no trato gastrointestina 1 , fatos que demonstram a ação efetiva dos referidos aditivos contra a população microbiana (VER VAEKE et alii, 1979; VISEK, 1978).

\subsection{Modo de ação dos antibióticos ionoforos}

Os antibiōticos poliēteres de ācidos carboxīlicos, tais como a monensina, lasalocid, narasina e salinom $\underline{i}$ cina pertencem ao grupo dos ionoforos, que possuem a habilidade de aumentar ou facilitar o movimento de ions metálicos através das membranas biolögicas ou artificiais. Na realida de, tal habilidade é dada pela capacidade destes antibióticos 
se associarem a ions metālicos monovalentes ou divalentes, por meio de ligações tipo dipolo induzido, pontes de hidrogênio, Tigações hidrofilicas e forças de van der walls (ELSASSER, 1984; RUSSELL; 1987). Estes complexos fracos movimen tam-se livremente por uma camada lipidica ou interface orgânica, alterando o fluxo iōnico atravēs de um aumento na permeabilidade das membranas celulares. Como consequēncia, há uma alteração completa do balanço ãcido-bāsico das cé]ulas bacterianas, principalmente pela alteração no transporte dos ions hidrogēnio, fato que proporciona um efeito depressivo sobre a fisiologia destes microrganismos (ELSASSER, 1984; BERGEN \& BATES, 1984).

A açäo seletiva destes ionoforos contra a maio ria das bactērias gram-positivas estä associada à presença de uma ünica membrana citoplasmātica, o que as faz mais sensîveis porque parece ser que o único sistema de obtençāo de ener gia é a via de fosforilação a nīvel de substrato (BARILEY et a $1 i i, 1979$ e NAGARAJA et alii,.1986. Em contraste, algumas bactê rias gram-positivas e as gram-negativas (a maioria) normalmente sobrevivem na presença de jonoforos. Tais microrganis mos possuem uma dupla membrana e geralmente têm outro sistema enzimātico (via fumarato redutase) que é uma via alternativa de produção de ATP. Desta forma, em presença de ionofo ros, este sistema $\bar{e}$ a opção da produção de energia para as bactérias, evitando a lise das cēlulas (BERGEN \& BATES, 1984; ELSASSER, 1984 e RUSSELL, 1987). 


\subsection{Os efeitos dos jonoforos na fisiologia e metabolismo do hospedeiro}

Os ionoforos salinomicina, monensina, lasalocid e narasina vēm sendo pesquisados como promotores do crescimento, principaimente de aves e de ruminantes. A salinomicina tem um modo de ação semelhante ao da monensina: ambas exíbem afinidade por cátions monovalentes, principalmente pelo sōdio $\left(\mathrm{Na}^{+}\right.$L e potássio $\left(K^{+}\right.$L. Jä a lasalocid apresenta maior afinidade por ions divalentes como o cālcjo $\left(\mathrm{Ca}^{++}\right)$. Quanto à narasina, trata-se de um ionoforo novo que apresenta afinidade por sōdio (Na) e potássio (KL) (TONKINSON et alii, 1982; ELSASSER, 1984; GUILLESPIE et alii, 1.984; RUSSELL, 1987).

Os ionoforos alteram a fisiologia do hospedeiro, atravess de um aumento na concentração de äcido propiōnico e diminuição dos ácidos acético e burítico no rúmen, intestino grosso e no sangue dos ruminantes (LEMENAGER et alii, 1278a,b; PRANGE et alij, 1978; KIRK et alij, 1985a,b e BARCLAY et alij, 1986 L e no intestino grosso e sangue dos suinos (HOLZgRAEFE et alii, 1985al. Como consequêncja deste aumento de àcido propiónico o animal poupa uma maior energia pois o ācido propiónico é mais eficientementécutilizado pelo hospedeiro por ter um menor incremento calórico que o acetato (BALDWIN \& ALLISON, 1983L. Desta maneira, ha uma maior quantidade de energia metabolizavel disponivel para o animal e também uma poupança de aminoảcidos normalmente utilizados para gluconeogênese, estimulando desta maneira a sintese de proteîna corporal (BERGEN \& BATES, 1984). 
Uma outra maneira de alterar a fisiologia do hospedeiro è aumentando a absorção de aminoācidos sujeitos a gradientes eletroquímicos ou osmóticos, consequēncia de uma redução na espessura das paredes intestinais. Em adição, alguns sistemas de absorção de nutrientes dependentes de gra diente elëtrico, excitabilidade e osmorregulação tambēm pode riam estar sendo modificados pelos ionoforos (BERGEN \& BATES, 1984).

Segundo ELSASSER (1984), o fluxo de Tons è al terado intra e extracelularmente com a adição de ionoforos,e o organismo do animal precisa de tempo para a liberação e captura de jons. Não se sabe com que intensidade a fisiolo gia normal do hospedeiro poderia ser mudado pelos ionoforos devido a uma possivel interrupção no fluxo ionnico, uma vez que o animal possui mecanismos de ação relativamente rápida para a manutenção da homeostase.

Por outro lado, os efeitos sistēmicos, que poderiam influenciar no metabolismo do animal pela alteração de mecanismos eridōcrinos, podem ser significativos. Assim, - ācido propiōnico induz a Tiberação de insulina no sangue, proporcionando uma maior entrada de glucose e aminoäcidos nas células e, como consequéncia, uma maior produção de energia, um aumento na sintese de proteîna muscular e uma diminuição do "turnover" de proteinna nos tecidos, fatos que contribuem para uma velocidade maior de crescimento dos animais (ELSASSER, 1984; BERGEN \& BATES, 1984; ARMSTRONG \& SPEARS, 1988). 
Um outro efeito sistêmico dos ionoforos, quando fornecido em pequenas doses, è a vasodilatação das coronā rìas, a qual $\bar{e}$ mediada, em parte, pela liberação das catecoTaminas EELSASSER, 1984 L.

2.4. A salinomictna outros ionöforos: suas aplicações nas diferentes especies animais 2.4.1. Aves

A salinomicina foi classificada como um ionoforo monovalente, que possui afinidade, principalmente, por ions $K^{+}$. Este efeito jonofórico sobre a parede celular é a base para seu uso como um eficiente coccidiostático de amplo espéctro em frangos de corte (WHEELHOUSE et alii, 1985), assim como para a promoção do crescimento nesta espécie do mëstica (DANFORTH et alii, 1977al. E importante ressaltar aịnda que, nas comparaçōes com outros jonoforos como a narasina, monensina e lasalocid (CHAPPEL \& BABCOCK, 1979 e GILLESPE et alii, 1986L, a salinomicina tem se mostrado mais eficiente no referente à atividade sobre as cepas de coccidia e no ganho de peso (DANFORTH et alij, 1977a,b;. GHAPPEL \& BABCOCK, 1979; HARMS \& BURESH, 1987 e AVICULTURA INDUSTRIAL, 1988L. A sua eficiência em relação à monensina e o lasalocid tem sido ainda maior em frangos de corte alimenta- 
dos com raçōes deficientes em proteĩnas ou em aminoäcidos sulfurados (HAMMANT, 1985L.

Quanto a possiveis efeitos prejudiciais, temse observado que ionoforos como monensina em nivejs elevados (mais de $100 \mathrm{ppm} L$ podem provocar problemas de enpenamento deficiente em frangos de corte. Tal efeito, segundo RILEY et a 1 ì (1986 [, poderia ser consequẽncia de uma alteração no trans porte de amonoa cidos nos tecidos, modificando o perfil de ami-. noäcịdos no cērebro o suficiente, para afetar negativamente o consume de alimentos. O mecanismo seria semelhante àquele enyolvido numa situação de desbalanço dietético de aminoácidos. Assim, estes autores recomendam aumentar os niveis dietéticos de arginina, triptofano e isoleucina, quando a monensina for fornectida em rações de frangos de corte.

A utilizaçäo da salinomicina em raçōes para perus tem resultado em respostas negativas no crescimento. Estes animais ao contrário de frangos de corte, tem mostrado uma grande sensibilidade a este ionoforo. Assim, perus alimentados com raçöes com niveis de 22 ppm de salinomicina apresentaram uma redução na raxa de crescimento e, com 35 ppm de monensina, stinais evidentes de tocixidade tem sido observados (HAL VORSON et alii, 1983; POTTER et alii, 1986). Para frangos de corte, por outro lado, sô com nîveis acima de $85 \mathrm{ppm}$ de monensina $\bar{e}$ que os sinais de toxicidade foram detectados (dificuldade respiratória, relutāncia do movimento e mortel. Estes sinais de toxicidade são mais evidentes em frangos com 
idade mais avançada (HALVORSON et alii, 1983; POTTER et a] i i, 1986).

\subsubsection{Ruminantes}

As pesquisas com os ionoforos monensina e lasalocid têm se concentrado mais na ärea de nutriçāo de ruminantes, onde os beneficios destes aditivos são mâis evidentes. A salinomicina têm sido estudada com menor intensidade. mas é a partir dos estudos desenvolvidos com os dois primeiros ionoforos, principalmente com a monensina, que tem-se ten tado explicar melhor o modo de ação da salinomicina.

A utilização de ionoforos acarreta uma mudança nos padrões da fermentação ruminal, através de uma ação seletiva contra bactérias gram-positivas. As mudanças que acontecem no rúmen são: alteração na proporção dos producios finais da fermentaçäo, através de um aumento na produção e concentração de ācido propiónico e uma diminuição dos äcidos acētico e butỉrico (redução na relação acētico:propiōnico); diminuição da produção de âcido lātico; e diminuição na produçâo de metano, devido a uma menor produção de hidrogēnio pelas bactërias celulolïticas. Também tem sido observado uma diminuição na proteōlise bacteriana e deaminação de proteî nas dietéticas, prejudicando a eficiencia de crescimento dos microrganismos do rúmen (PRANGE et alii, 1978; BERGEN \& BATES, 1984; ELSASSER, 1984; NAGARAJA et alii, 1986; RUSSELL, 
1987). Todas essas mudanças nos padrões de fermentação, pro porcionadas pelos ionoforos monensina e Tasalocid foram, tam bém, observadas nos estudos com salinomicina em novilhos (FON TENOT et a $1 \mathrm{i} i, 1980$; MERCHEN \& BERGER, 1985; BARCLAY et a $1 \mathrm{i}$, $1986)$.

Os ionoforos possuem a capacidade de reduzir a taxa de renovação ruminal de sólidos e líquidos. Desta maneira, o consumo de forragens pelos animais, recebendo monensina ou lasalocid, é diminuido (LEMENAgER et alii, 1978b) e a conversão alimentar é melhorada, mesmo em animais recebendo forragens e/ou concentrado (DINIUSetalii, 1976; LEMENAGER, 1978a e PENDLUM et alij, 1978). Respostas semelhantes foram encontradas com a salinomicina fornecida a novilhas em paste jo (MCCLURE et alii, 1980; WEBB et alij, 1980; BARCLAY et alii, 1986; BAGLEY et alii, 1988 e SPROTT et alii, 1988) ou a yacas e ovelhas em confinamento (MERCHEN \& BERGER, J85). Na realidade, todos os ionoforos têm proporcionado aumentos no ganho diārio de peso ou uma melhora na performance geral dos animais (LEMENAGER et alii, 1978a;.PEND LUM et alii,, 1978 e SPROTT et alii, 1988). Tais efeitos favoráveis podem ser consequēncia, em parte, de um aumento na digestibi lidade da matéria seca, dos componentes da fibra e do nitrogê nio, tanto em bovinos como em ovinos (WEBB et alii, 1980; MERCHEN \& BERGER, 1985 e BARCLAY et alij, 1986).

$$
\text { os ionoforos têm-se mostrado, tambëm, serem }
$$
eficientes agentes contrārios à acidose lática e ao empazina 
mento em ruminantes. No primeiro caso, a presença dos iono foros monensina e lasalocid em dietas ricas em alimentos concentrados acarretou uma diminuição das bactērias responsāveis pela produção de lactato ruminal, tanto 'in vivo' (BERGEN \& BA TES, 1984I como. "in vitro' (NAGARAJA et alji, 1986). No caso do empanzinamento, os ionoforos diminuem a viscosidade do fluỉdo ruminal, talvez deyido a uma diminuição no nümero de protazoârios responsāveis pela produçäo de mucus, particularmente quaindo a a timentaçäo é rica em concentrado (MERCHEN \& BERGER, 1985 e RUSSELL, 1987L.

\subsubsection{Suínos}

As pesquisas desenvolvidas com a salinomicina, como aditịvo de raçōes de suinos, têm mostrado efeitos benéf̣̂cos, quando utilizada ate o nível de $110 \mathrm{ppm}$. Os benefictos, na realidade, têm sido observados em suinos da desmama do abate (BLAIR \& SHIRES, 1981 ; STAHLY et alii, 1980 e LINDEMANN et aliț, 1985) ou em animais em crescimento-acabamento (LEESON et alit, 1981; SHIVELY et alii, 1982a,b; WHEELHOUSE \& GROVES, 1285 e BUHME \& OSLAGE, 1986L.

De maneira geral, os efeitos favoráveis da salinomicina sobre a conversäo alimentar e o ganho de peso dos suTnos têm variado, respectivamente, de 3 a $12 \%$ e 1 a $8 \%$ CBLAIR \& SHIRES, 1981; LEESON et aIji, 1981; SHIVELY et alij, $1282 \mathrm{a}$; De WILDE, 1984 ; LINDEMANN et alii, 1985; BOHME \& OSLAGE, 1986 
e BANE et alit, 1988L. Estas melthoras independem do sexo (WHEE LHOUSE \& GROVES, 1985 L; da forma de manejo na alimentação (ã vontade ou restrital e da performance dos animais controle (BOH ME \& OSLAGE, 1986 L.

Em estudos comparativos, suinos suplementados com a salinomicina apresentaram melhores conversões alimentares e ganhos diārios de peso do que aqueles suplementados com outros antibióticos, como a viginiamicina, tilosi na ou tilosina mais flavofoslipol (SHIVELY, 1982b; LINDEMANN et alit, 1985 e BOHME \& OSLAGE, 1986). Contudo, o consumo de raçäo näo foi superior, quando comparado com os animais alimentados com rações contendo carbadox (BLAIR \& SHPRES, 1981 I.

Na realidade, hä indicaçöes de que a salinomicina apresenta efeitos benéficos na digestibilidade dos nutrientes em suinos. Sabe-se que a fibra pode influenciar a performance dos suinos, especialmente nas fases de crescimento e acabamento, atravēs da redução na digestibilij-ade do ni trogêntio e doa aminoācidos (KENNELLY \& AHERNE, 1980 e VAREL et alłi, 1984 I assim como tambēm na redução da digestibilidade aparente de energia, matéria seca e os componentes da fiEra tanto de leitões desmamados (MOORE et alii, 1988) como de marräs em gestação (HOLZGRAEFE et alij, 1985b e BANE et a) ไิ่, $1988[$.

A adição de antibióticos ionoforos como lasalocid e raçôes com niveis eleyados em fibra aumentou a absor- 
çäo aparente de nịtrogênio em marräs gestantes (HOLZGRAEFE et a]ti, 19855I. Isto poderia ser explicado porque a adicionarem antibiāticos às raçōes para os suĩnos, ocorreu uma diminuição das bactérias gram-positivas (especialmente E. coli), de reconhecida capacidade deaminadora (VERVAEKE et alij, 1979). Os antíióticos diminuem a capacidade de sỉntese pelas bacté rias por uma inibição da sua atividade ribosomal, fazendo entäo com que o nitrogênio dietético seja poupado e absorvido peto hospedeiro (EGGUM et alii, 1982).

Hă tambëm indicações de que a salinomicina pode melhorar a qualidade de alimentos com conteúdos eleva dos de fibra. Assim, MOORE et alij (1986a), utilizando duas fontes de fibra, diferentes na sua degradabilidade (casca de aveia e farelo de trigol com ou sem $85 \mathrm{ppm}$ de salinomicina/kg na raçäo, observaram os efeitos favorāyeis deste antibiótico sobre a digestibilidade da matéria seca e a disponibili dade de energia e nitrogenjo. No entanto, näo houve diferença na digestibilidade da fibra detergente neutro, celulose e hemiceluiose, Por outro lado, WORDU et alii (1985) encontraram que a salinomicina melhorava a digestibilidade da fibra detergente neutro do farelo de cevada em suinos.

Segundo HOLZGRAEFE et alii (1985a), num estudo de digestibilidade 'in vitro', a fonte de fibra pode alterar a atividade microbiana e o tempo de passagem da digesta dos conteüdos cecais em marrās: mas a adição de lasalocid à rações contenda a farinha de alfafa e orchardgrass aumentou a taxa 
de retenção da digesta, melhorando a utilização dos componentes da fibra nos animais. Por outro lado, o lasalocid alterou as proporçōes dos äcidos graxos voläteis, aumentando as concen trações de ācido propiônico e diminuindo as concentrações de äcido acētito e butïrico (HOLZGRAEFE et a1ii, 1985a; WPRDU et a]ji, 1985L, sendo que o àcido propiônico è um precursor de glucose e a contribuição dos äcidos graxos varia de $5-28 \%$, a maior produçäo de propiônico no trato intestinal poderia aumentar a utịizaçäo de energia pelos suínos (HOLZGRAEFE et a 11$\}, 1985$ a $[$.

o balanço mineral dos suínos também pode ser influenciado pelos antibióticos, quando fornecidos em dietas com elevados niveis de fibra. Assim, RAVINDRAN et alii [1984 [ encontraram que a viginiamicina aumentava a absorção e retenção de câlcio, fósforo, magnésio, cobre, ferro, zịnco e magnésio nos suínos na fase de crescimento. Por outro lado, os antibióticos ionoforos como a salinomicina (MOORE et alii, 1286bl e lasalocid (HOLZGRAEFE et alii, 19855 L tiveram uma marcada infiuência sobre a utilização de minerais especialmente de cálcio, fósforo e potássio de dietas altamente fibrosas como feno de alfafa e orchardgrass para marräs grävidas e farelo de trigo em suinos em crescimen to. No entanto, parece que esta não $\vec{e}$ uma regra geral, pois tal fato nậo foi observado no experimento de MOORE et alij (12866L, quando o ionoforo foi adicionado a casca de aveia co 
mo fonte de fibra. Possivelmente, o elevado conteúdo de fita tos na casca de aveia seja o responsāvel pela indisponibilidade de cālcio, fósforo e zinco aos animais. 


\section{MATERIAL E METODOS}

\subsection{Local e Anima is}

O presente estudo foi realizado no setor de Suinocultura do Departamento de Zootecnia, da Escola Superior de Agricultura "Luiz de Queiroz", Universidade de São Paulo, Piracicaba, SP. Mais especificamente, esta pesquisa foi conduzida numa creche experimental equipada com 20 gaiolas metálicas suspensas, de $1,50 \times 1,20 \mathrm{~m}$, com piso parcialmente ripado, dotadas de bebedouros e comedouros automáticos e aquecedores com lâmpadas infra-vermelhas de 250 watts de potência.

Foram utilizados 85 leitões tri-cross (Landrace $\times$ Large white $\times$ Duroc), com peso médio inicial 10,77 kg, sendo distribuidos aos tratamentos de acordo com o peso e sexo.

\subsection{Ração basal e Tratamentos}

A composição quîmica, assim como a energia di 
gestível dos ingredientes são apresentados na Tabela 2 . A anălise quîmica bromatológica foi realizada no laboratōrio de bromatologia do Departamento de Zootecnia ESALQ/USP, segundo os metodos descritos pela ASSOCIATION OF OFICIAL AGRICULTU RAL CHEMISTS (1965). A composição percentual da dieta basal com $18 \%$ de proteína bruta $(P B)$ e $3.386 \mathrm{Kcal}$ de energia diges tiva (ED) é mostrada na Tabela 3.

Os animais foram distribuídos a 5 tratamentos que correspondiam a $0,25,50,75$ e 100 ppm de salonomicina na ração. Utilizou-se um delineamento experimental em blocos casualizados, com 8 repetições por tratamento e 2 (B1o$\cos 1,3,4,5,6,7$ e 8 ) ou 3 (B10co 2) animais por unidade experimental.

\subsection{Manejo e colheita de dados}

As rações experimentais (na forma peletizada) foram fornecidas à vontade aos animais, durante um período de 28 dias. As pesagens individuais dos leitoes e a coleta dos dados de consumo de ração/parcela foram fejtas semanalmente. A conversão alimentar foi obtida a partir do consumo total de ração e do ganho de peso total de cada unidade expe rimental. 
Tabela 2. Composição quîmica e energia digestîvel dos ingredientes?.

\begin{tabular}{|c|c|c|c|c|c|}
\hline \multirow{2}{*}{ Componentes } & \multicolumn{5}{|c|}{ Ingredientes } \\
\hline & Mitho & $\begin{array}{c}\text { Farelo } \\
\text { soja }\end{array}$ & $A c ̧ u \bar{c} a r^{2}$ & $\begin{array}{l}\text { Fosfato } \\
\text { biçâlcico }\end{array}$ & $\begin{array}{l}\text { Carbonato } \\
\text { de cālcio }\end{array}$ \\
\hline Matéria seca, \% & 86,81 & 88,45 & 99,69 & - & - \\
\hline Proteina bruta, $\%$. & 8,51 & 45,15 & 0,08 & - & - \\
\hline Fibra bruta, $\%$ & 2,06 & 5,58 & - & - & - \\
\hline Extrato etēreo, \% & 3,97 & 2,64 & - & - & - \\
\hline Materia mineral, \% & 1,09 & 6,13 & - & - & - \\
\hline Extr. não nitrogenado, \% & 71,18 & 28,96 & 99,07 & - & - \\
\hline Lisina, $\% 2$ & 0,23 & 2.87 & - & -. & - \\
\hline Triptofano, $\% 2$ & 0,08 & 0,67 & - & - & - \\
\hline Metionina + cistina, $\% 2$ & 0,35 & 1,34 & - & - & - \\
\hline Cärcio, \% & 0,01 & 0.32 & - & 26,00 & 39,5 \\
\hline Fösforo, $\%$ & 0,20 & 0,55 & - & 19,04 & - \\
\hline En. digest., $\mathrm{k} \mathrm{cal} / \mathrm{kg}^{2}$ & 3493 & 3378 & 4124 & - & - \\
\hline
\end{tabular}

1 Laboratörio de Bromatologia do Departamento de Zootecnia/ESALQ/USP.

2 ROSTAGNO et alii (1983) 
Tabela 3. Composição percentual da ração basal.

Ingredientes

Mitho

Farelo de soja

Açūcar

Fosfato bicālcico

Carbonato de cálcio

Sal

Premix Vitaminico 1

Premix minerai. ${ }^{2}$
$\%$

65,61

27,50

4,00

1,62

0,60

0,50

0,10

0,07

Valores calculados:

Energia digestivel, $\mathrm{kcal} / \mathrm{kg}$

3386

Proteina bruta, \%

18,00

Lisina, \%

0,94

Triptofano, \%

0,20

Metionina + cistina, \%

0,60

Cálcio, \%

0,75

Fósforo, \%

0,59

Suprindo as seguintes quantidades por $\mathrm{kg}$ de ração: Vit. A. 12.000 UI; Vit. $D_{3}, 1.500$ UI; Vit. E, 15 UI; Vit. $\mathrm{K}_{3}, 3 \mathrm{mg}$; tiamina, $2 \mathrm{mg}$; riboflavina, $4 \mathrm{mg}$; niacina, $20 \mathrm{mg}$; ácido pantotênico, $15 \mathrm{mg}$; Vit. B12, $20 \mathrm{mcg}$; àcido fólico, $0,6 \mathrm{mg}$; biotina, $0,10 \mathrm{mg}$ e colina, $100 \mathrm{mg}$.

2 suprindo as seguintes quantidades por $\mathrm{kg}$ de ração:

$\mathrm{Fe}, 126 \mathrm{mg} ; \mathrm{Cu}, 21 \mathrm{mg}$; $\mathrm{Co}, 2,8 \mathrm{mg} ; \mathrm{Mn}, 5,6 \mathrm{mg} ; \mathrm{Zn}, 9.8 \mathrm{mg} ;$

I, $2,8 \mathrm{mg}$. 
Ao final do experimento foi feita a coleta de sangue da veia cava anterior de todos os animais (sem jejum) em seringas de $10 \mathrm{ml}$ molhadas com solução äcido etileno-diamino-tetracêtico (EDTA) a $10 \%$. 0 sangue coletado na seringa era transferido a um tubo de ensaio que continha $0,10 \mathrm{ml}$ de EDTA a $10 \%$ para ser homogeneizado, agitando o tubo ientamente por 3 vezes. Logo após a coleta, cada amostra de sangue foi dividida em 2 sub-amostras e mantidas em gelo para posterior manuseio em laboratōrio. De uma das sub-amostras, separou-se o plasma por centrifugação a $3.000 \times \mathrm{g}$ por quinze minutos. Em seguida, prepararam-se amostras compostas do plasma dos leitōes pertencentes a uma baia (em volumes equivalentes) que correspondia a uma unidade experimental.

A segunda sub-amostra de sangue e as amostras composta de plasma foram mantidas em refrigeração por 24 ho ras e, depois, enviadas para o laboratōrio de Anāiises Clíni cas Humana PREVLAB, em Piracicaba - Estado de São Paulo, com a finalidade de se realizarem as anāises dos componentes. A hemoglobina foi determinada pelo método de cianometahemo globina e o hematócrito pelo mētodo de microcentrifugação. As frações uréia, proteína total, albumina e triglecerídios do plasma, foram dosados em um autoanalisador. Technicon SMA 12 160. Os niveis de globulina foram obtidos por diferença entre a proteina total e a albumina conforme BERTO (1985) e 
MIYADA (1987). Assim, uma vez calculado o conteüdo de globu从 lina, pôde-se obter a relação albumina/globutina.

\section{4: Anālise estatística}

Os dados de performance e componentes sanguineos foram submetidos à anālise de variāncia (STEEL \& TORRIE, 1980), utilizando o programa SANEST - Sistema de Anä7ise Estatîstica (ZONTA, 1983), no Centro de Informätica na Agricultura da ESALQ/USP, Piracicaba, SP. Os graus de liber dade dos tratamentos (nĩveis de salinomicina na ração) foram decompostos em seus componentes individuais (linear, quadrātico, cūbico e de 49 grau), atravēs dos polinōmios ortogonais. 


\section{RESULTADOS E DISCUSSÃO}

\subsection{Caracteristicas de performance}

Os parāmetros utilizados para avaliar a performance de suinos foram: ganho diārio de peso (GDP), consumo diārio de ração (CDR) e conversão alimentar (CA). Os resultados são apresentados na Tabela 4. Os valores originais dos dados de performance são apresentados na Tabela A1, no Apēndice.

0 aumento do nível de salinomicina na dieta proporcionou uma resposta quadrātica $(P .<0,01)$ do ganho dịa rio de peso, uma resposta linear $(P,<0,02)$ e quadrática $(P-<$ $0,03)$ no consumo diārio de ração e uma melhora linear $(P$. $0,02)$ da conversão alimentar. Tais respostas podem ser descritas respectivamente pelas equações $G D P=0,49039+0,00195 X$ - $0,00002 x^{2} ; \quad \operatorname{CDR}=1,000339+0,002282 x-0,000032 x^{2}$ e $C A=$ $2,04750-0,00105 X$, onde $X$ representa o nível de salinomicina na ração. Estas respostas são ilustradas nas figuras 1 e 2 . 
Tabela 4. Médias das caracterīsticas de performance dos suĩnos em recria, alimentados com rações contendo niveis crescentes de salinomicina.

\begin{tabular}{|c|c|c|c|c|c|c|}
\hline \multirow{2}{*}{ I tem } & \multicolumn{4}{|c|}{ Niveis de salinomicina na ração, } & $\mathrm{ppm}$ & \multirow{2}{*}{ C.V. $\%^{\mathrm{a}}$} \\
\hline & 00 & 25 & 50 & 75 & 100 & \\
\hline Nümero de animais & 17 & 17 & 17 & 17 & 17 & \\
\hline Peso médio inicial, $\mathrm{kg}$ & 10,63 & 10,90 & 10,77 & 10,75 & 10,83 & 2,36 \\
\hline Peso médio final, $\mathrm{kg}$ & 23,63 & 24,99 & 24,95 & 24,48 & 23,89 & 5,90 \\
\hline \multicolumn{7}{|l|}{ Caracterīstica de performance: } \\
\hline Ganho diārio de peso, $\mathrm{kg}^{\mathrm{b}}$ & 0,488 & 0,533 & 0,533 & 0,517 & 0,479 & 10,44 \\
\hline Consumo diārio de ração, $\mathrm{kg}^{\mathrm{C}}$ & 0,991 & 1,060 & 1,018 & 0,984 & 0,905 & 9,80 \\
\hline Conversão alimentar $\mathrm{d}$ & 2,071 & 1,999 & 1,929 & 1,970 & 1,903 & 6,71 \\
\hline
\end{tabular}

a Coeficiente de variação

b Efeito quadrātico $(P<0,01)$ dos nīveis de salinomicina na ração

C Efeito linear $(P<0,02)$ e quadrātico $(P<0,03)$ dos nïveis de salinomicina na ração

d Efeito linear $(P<0,02)$ dos nĩveis de salinomicina na ração. 

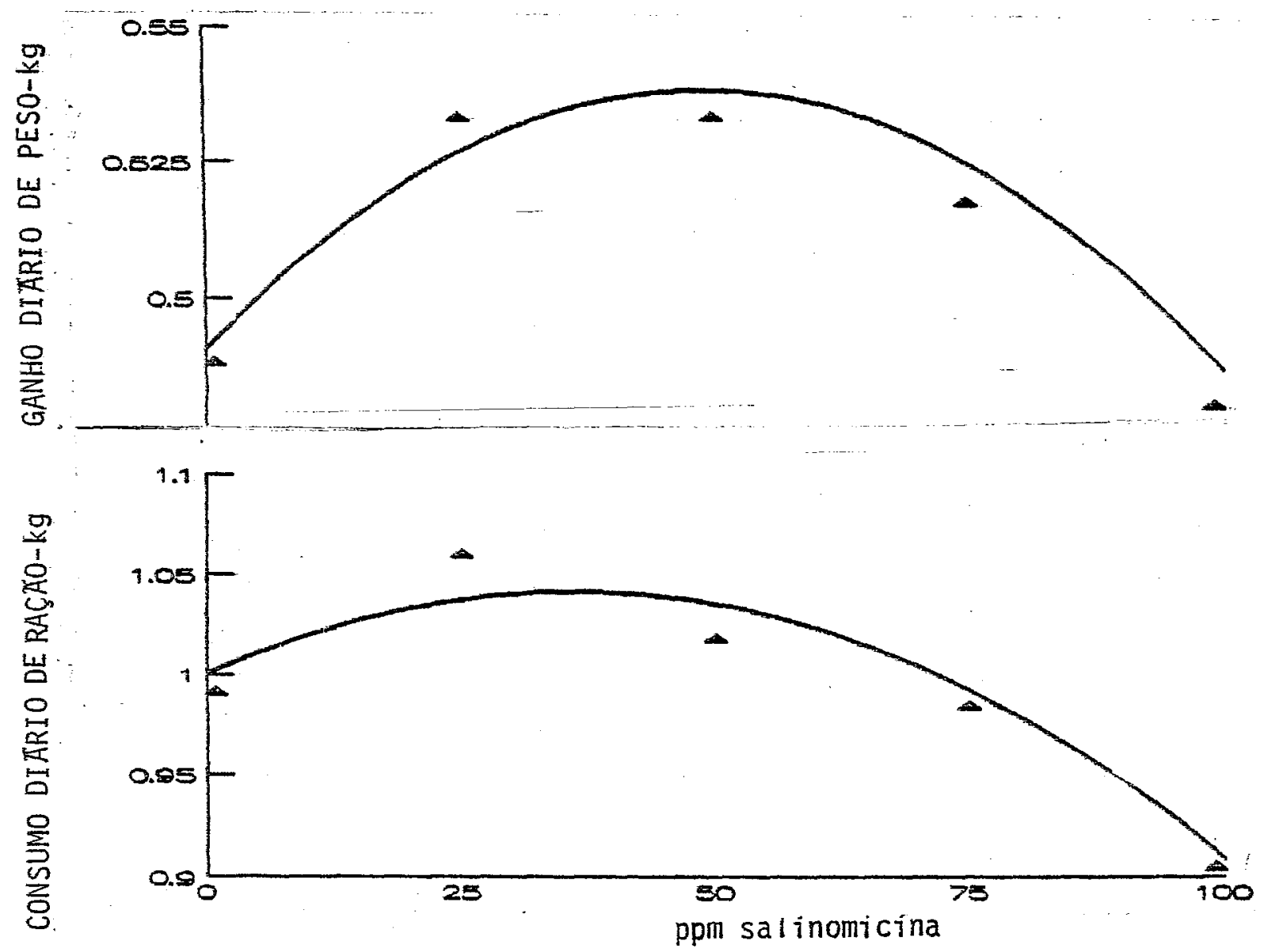

Figura 1. Efeitos dos niveis de salinomicina sobre o ganho diärio de peso e consumo diärio de raçäo.

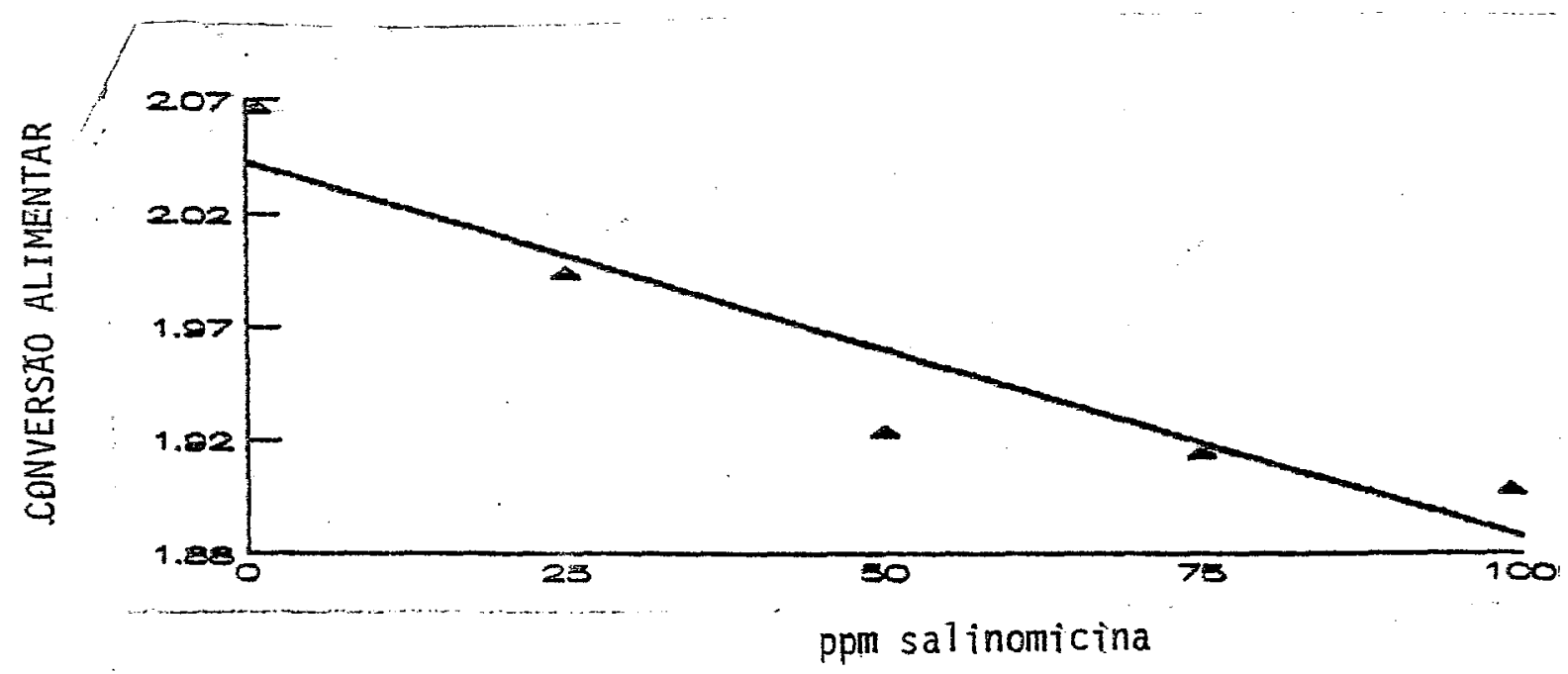

- Figura 2. Efeito dos niveis de salinomicina sobre a conversão al imentar. 
o major ganho diārio de peso foi alcançado com um nivel de $49 \mathrm{ppm}$ (calculado) da salinomicina na ração. Gran de parte deste ganho possivelmente se deva a a umento do consumo diārio de ração (até 35 ppml estimulado pela salinomicina. Respostas semeihantes tambēm foram observadas nos estu dos de BLAIR \& SHIRES (19.81) e LINDEMANN et alij (1985), utiJizando niveis entre 27 e $85 \mathrm{ppm}$ de antíbiötico em rações de suĩnos de 8 a $40 \mathrm{~kg}$ de peso vivo. A outra parte do aumento no ganho diärio de peso dos animais talvez se deva a um aumento na utilização de nutrientes, conforme mostra a conversăo alimentar, que teve uma melhora contỉnua até o nível de $100 \mathrm{ppm}$. Um efeito benéfico da salinomicina sobre a conversão alimentar jä havia sido relatada anteriormente pelos autores mencionados.

As respostas beneficas da salinomicina sobre o ganho diário de peso, obtidas no presente experimento, confir mam as encontradas pelos pesquisadores que trabalharam com suinos nas fases de crescimento-acabamento (LEESON et alii, 1981; WORNICK et alii, 1983; LINDEMANN et alii, 1985; WHEELHOU SE \& GROVES, 1985 e BOHME \& OSLAHE, 1986L.

Por outro lado, os resultados para 100 ppm de salinomicina no ganho diärio de peso pode indicar uma re dução deste parâmetro, possivelmente devido a um efeito depressivo no consumo diário de ração.

os resultados favoráveis da salinomicina sobre 
a conversão alimentar, obtidos neste experimento confirmam aqueTes encontrados em outros trabalhos anteriormente realizados com suĩnos em recria (WILDE, 1984 e LINDEMANN et alii, 1985), em que nîveis de atê $85 \mathrm{ppm}$ deste ionóforo foram utilizados. Alêm disso, resultados semelhantes têm sido relatados para a conversão alimentar de suînos em crescimento-acabamento (LEESON et a ii 1981 e BOHME \& OSLAGE, 1986) quando do uso de 25 e 50 ppm de salinomicina:

Os resultados do presente experimento sugerem que, alēm da ação ionoforética da salinomicina, outros mecanis mos poderiam estar envolvidos de forma semelhante a dos antibióticos tradicionais, onde a ação ê principalmente através de perdas menores de nutrientes. Talvez tenha sido esta a for ma em que a salinomicina no presente experimento demonstrou ser favorävel a uma melhor performance de lejtōes em recria, a exemplo de outros antibióticos como a virginiamicina ppmL, utilizada por LANGOIS et alii (1978), ou a virginiamicina $(27,5 \mathrm{ppm})$ associada ao cobre $(250 \mathrm{ppm})$, ou a clortetra ciclina (50 ppml com sobre (250 ppm) como mostram os trabaThos de STAHLY et alii (1980L e RIBEIRO DE LIMA et alii (1981). Alëm disso, estes autores explicam estas respostas como sendo devido a um efeito aditivo do cobre mais os antibióticos.

Por outro lado, observou-se que por algum meca nismo a salinomicina influenciou o consumo negativamente a partir de 50 ppm, apesar de melhorar a conversão alimentar, con 
forme $j \bar{a}$ foi mostrado em aves alimentadas com $100 \mathrm{ppm}$ de monensina num estudo realizado por RILEY et alij (1986). Segundo estes autores, o efeito depressivo do ionoforo sobre o consumo de ração seria causado por uma alteração no transporte de aminoácidos, influenciando, desta maneira, os centros nervosos, normalmente, envolyidos no controle do consumo. Nesta situação, o animal (avel, geralmente, exibe um quadro semeThante àquele mostrado pela deficiencia de aminoảcidos sulfurados na ração.

Ressalte-se, ainda, que a salinomicina pode ter promovido o aumento da performance dos leitöes, através de uma melhora na eficiencia de utilizaçāo dos carboidratos estruturais, embora para esta categoria de suinos em recria o mais provāvel mecanismo de açăo seja, possivelmente, semelhan te àquele dos antibióticos tradicionais. Este antibiótico io noforo contribui no aumento da produção de ácido propiónico (que estimuta a liberação de insulina), por mudanças no metabolismo energētico bacteriano, alterando a produção de ácidos graxos voláteis a nível de rümen de bovinos e ovinos (BARCLAY et alii, 1986; WEBB et alii, 1280 e BAGLEY et alii, 1988). Alēm disso, um ionoforo pode proporcionar uma maior absorção e retenção de ions essenciais como magnésio, cālcio, fosfato, zinn co, södio e potássio nos tecidos, conforme foi demonstrado nos estudos realizados com ovelhas (KIRK et alij, 1985a,bl. Em suînos, tem-se observado que a salinomicina aumenta a produ- 
ção de ácido propiónico no intestino delgado e intestino gros so, assim como a digestibilidade da matéria seca de outros nu trientes como carboidratos, nitrogênio possivelmente, mine rais, como indicam os resultados obtidos por MOORE et alii $(1986 a, b)$.

Por outro lado, a alteração da permeabilidade das membranas (ELSASSER, 1984 e BERGEN \& BATES, 1984) leva ria a uma alteração nas concentrações de sōdio e de cālcio necessārios para o acoplamento entre o estīmulo e a secreção Cou liberaçãol de hormónios das cälulas. Como exempios de hormônios que, possivelmente, dependam dos ïons sódio e cālcio para sua secreçăo, podem ser citados os hormônios liberadores de gonadatropinas, hormōnio do crescimento e o hormônio luteinizante. Há indicações de que os efeitos sejam indiretos, atravēs de uma estimulação de catecolaminas ou por uma alteração do sistema AMP cî́clico ou hormōnio segundo mensage ro (ARMSTRONG \& SPEARS, 1988). Assim todos estes mecanismos podem estar envolvidos na promoção do crescimento dos animais.

\subsection{Componentes sanguíneos e plasmáticos}

Na Tabela 5, são apresentados os resultados médios dos componentes sanguíneos (hematócrito e hemoglobinal e plasmáticos (urểia, proteîna total, albumina, globulina, re lação albumina/globulina e triglicerîdiosl. Os valores ori- 
Tabela 5. Médias dos componentes sanguĩneos e plasmäticos dos suĩnos em recria, alimentados com rações contendo niveis crescentes de salinomicina.

\begin{tabular}{|c|c|c|c|c|c|c|}
\hline \multirow{2}{*}{ Item } & \multicolumn{4}{|c|}{ Niveis de salinomicina na ração, } & ppm & \multirow{2}{*}{ C.V. $(\%)^{a}$} \\
\hline & 00 & 25 & 50 & 75 & 100 & \\
\hline \multicolumn{7}{|l|}{ Componentes sanguĩneos: } \\
\hline Hematōcrito, \% & 34,41 & 34,71 & 35,25 & 33,88 & 32,94 & 6,55 \\
\hline Hemoglobina, $g / d l$ & 10,78 & 11,10 & 11,14 & 10,86 & 10,65 & 7,22 \\
\hline \multicolumn{7}{|l|}{ Componentes plasmäticos: } \\
\hline Urēia, mg/dl & 28,75 & 27,25 & 30,13 & 28,38 & 27,38 & 15,61 \\
\hline Proteina tota $1, g / d \mathrm{l}$ & 5,88 & 5,88 & 5,90 & 5,91 & 5,74 & 5,69 \\
\hline Albumina, g/dl & 3,09 & 3,23 & 3,23 & 3,79 & 3,16 & 8,18 \\
\hline Globulina, g/dl & 2,79 & 2,65 & 2,66 & 2,74 & 2,58 & 14,18 \\
\hline Relação altumina/globulina & 1,18 & 1,26 & 1,23 & 1,22 & 1,28 & 18,74 \\
\hline Triglicerĩdios, mg/dT... b & 65,38 & 58,50 & 52,25 & 59,50 & 50,38 & 15,94 \\
\hline
\end{tabular}

a Coeficiente de variação

b Efeito linear $(P<0,05)$ dos nîveis de salinomicina na ração. 
ginais dos dados dos componentes sanguineos e plasmáticos são apresentados na Tabela $A 2$, no Apêndice..

A adição de salinomicina na ração não influenciou $(P>0,05)$ os níveis de hematöcrito e hemoglobina no sangue dos suînos. As mëdias gerais destes dois parâmetros sanguineos foram similares àquelas apresentadas por POND \& MANER (1974), ETHERIDGE et alii (1984) e MIYADA (1987).

$E$ importante ressaltar que conteüdos de hemoglobina e bematócrito são basicamente indicadores do estado nutricional em fierro (POND \& MANER, 1974). O hematócrito e um reflexo do número de eritrōcitos e do conteúdo de hemoglobina do sangue dos animais (SWENSON, 1977), sendo que hă indicações de que o hematōcrito pode estar relacionado ao nîvel de lisina na ração (MIYADA, 1987). Neste experimento, os valores destes parâmetros estão dentro da faixa de normaTidade, indicando que a salinomicina não apresentou qualquer alteração significativa e póde manter um bom estado nutricional de ferro.

Quanto àos componentes do plasma sanguíneo, o nīvel de uréia não sofreu qualquer influēncia $(P \geq 0,05)$ da salinomicina na ração. Um dos mecanismos de ação da salino micina em melhorar a performance $\bar{e}$ atravēs de um aumento na incorporação de aminoäcidos (ELSASSER, 1984 e BERGEN \& BATES, 1984 L. Assim sendo, poder-se-ia esperar uma possīvel redução da uréia no plasma. No entanto, tal fato não foi observado no 
presente ensaio, indicando que, possivelmente, esse mecanismo possa não estar envolvido em leitões.

Na realidade, o nîvel de urēia no plasma é. um indicador do estado nutricional dos suinos em proteina. Assim, um nỉvel elevado de urēia plasmātica pode significar um desbalanço de aminoācidos na ração (TAYLOR et alij, 1981), um consumo de proteinnas de baixo valor biológico ou um consumo elevado de proteînas (PUCHAL et alii, 1962). Qualquer uma destas situaçōes acarreta perdas de nitrogênio na forma de uréia devido a uma menor sîntese de proteína corporal (ALLEN, 1970). Portanto, no presente ensaio, em que a uréia do plasma se manteve em niveis normais (POND \& MANER, 1974) näo ficou evidenciado qualquer tendēncia que pudesse indicar uma possivel melhora no aproveitamento das rações com o aumento dos niveis dietéticos de salinomicina.

- Quanto ao nivel de proteina total, estā den tro da faixa dos valores normais de 5,45 a $6,30 \mathrm{~g} / \mathrm{d} 1 \mathrm{de}$ plasma, relatada por MILLER et alii (1961), POND \& MANER(1974) e MIYADA (1987).

Os conteludos plasmäticos de albumina e globulina dos leitões encontram-se dentro da faixa da normalidade de suinos em acabamento (MILLER et alii, 1961L e semeihante aos valores encontrados por BERTO (1985) e MEYADA (1987) para suinos em recria. Tal fato $\vec{e}$ um indicativo de que o nîvel de proteîna da raçâo foi adequado, pois uma deficiência 
deste nutriente ou de um aminoäcido essencial poderia refletị numa diminuição da albumina no plasma, conforme afirmam POND \& MANER (1974).

A relação albumina/giobulina näo foì influencjada pelos nîveís de salinomicina na ração $(P>0,05 L$, sendo que os valores observados neste trabaitho foram semelhantes àqueles encontrados por BERTO (1981) e MIYADA (1987), cujos niveis médios foram de 1,16 a 1,29 .

Houve uma diminuição linear $(P<\theta, 01)$ no conteūdo de triglicerídios ( $T G L$ do plasma, à medida que o nível de salinomicina foi aumentado. Tal resposta pôde ser descrita pela equação $T G=63,000-0,1168 x$ cuja representação grāfica é mostrada na figura 3. Embora os dados de trigliceridios tenham mostrado uma variabilidade relativamente elevada $(C V=15,94 \%)$, o nỉvel deste componente plasmätico esteve dentro da faixa de 51,4 a $127 \mathrm{mg} / \mathrm{dl}$ de plasma, apresentado por HALE et alii (1286) e MIYADA (1987).

Normalmente, o nível de triglicerídios do plas ma é influenciado pelo nível de energia da raçäo (HALE etalii, 1986 e MIYADA, 1987/. Por outro lado, há evidências de que os ionoforos podem alterar a utilização de äcidos graxos pelo anima1. Assim, num trafalbo de ARMSTRONG \& SPEARS (1988), foi observado que a injeção do ionoforo monensina em bovinos dimịnuia os niveis de magnésio no sangue, um mineral envolvido na indução de lipólise, e também diminuia o nîvel de äcidos gra- 
xos livres no sangue. Tais fatos são indicações de que há melhor aproveitamento da energia da ração pelo animal, propor cionado pela monensina, um ionoforo semelhante à salinomicüna. Portanto, a redução linear do conteúdo de triğlicerídios do plasma dos leitões, proporcionado pela salinomicina, pode ter envolvido um mecanismo semelhante àquele descrito para monen: sina.

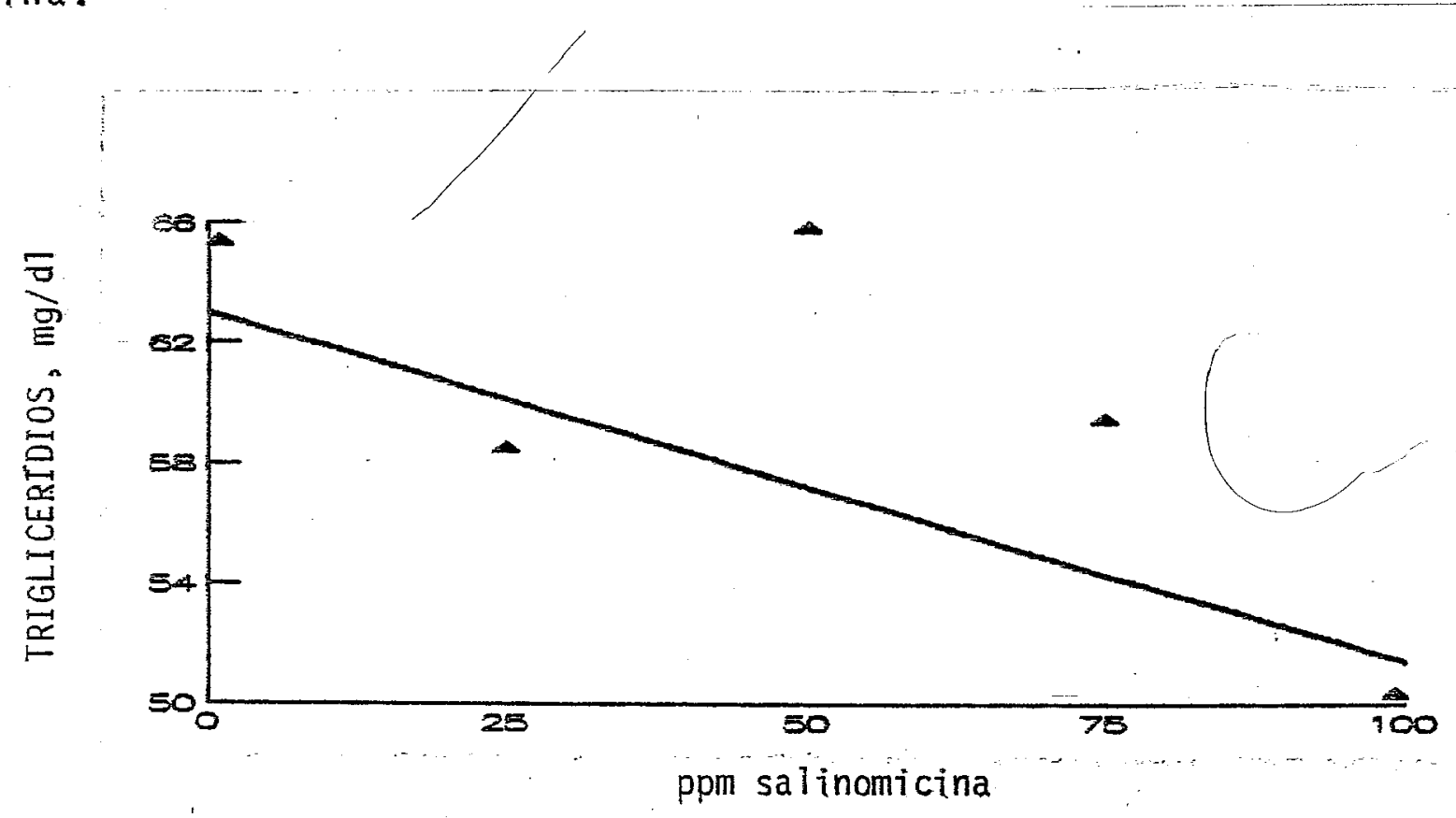

Figura 3. Efeito dos niyeis de salinomicina sobre os triglicerîdios do plasma de leitōes em recria. 


\section{CONCLUSÕES}

A adição do antibiōtico salinomiçina ã ração de leitões em recria (10 a $25 \mathrm{~kg}$ de PV), baseada em milho, fá relo de soja e açūcar, proporcionou respostas dos animais, que permitiram chegar a importantes conclusões:

- A salinomicina melhorou o ganho diārio de pe so atē o nīvel de 49 ppm na ração;

- O consumo diārio de ração dos animais foi es timulado até $35 \mathrm{ppm}$ de salinomicina na dieta;

- A conversão alimentar foi linearmente melhorada atē 100 ppm de salinomicina na ração;

- Há indicações de que a partir de 100 ppm de salinomicina na dieta, este antibiótico pode apresentar uma redução no ganho diārio de peso, possivelmente devido a um efeito depressivo no consumo diărio de ração;

- Os parâmetros sanguîneos, hemoglobina e hema tōcrito não foram afetados significativamente pela adição de salinomicina à dieta; 
- Os componentes plasmāticos urēia, proteîna to tal, albumina, globulina e a relaçäo albumina/globulina também näa foram influenciados pela salinomicina incorporada à dieta.

- Os triglicerídios do plasma foram diminuidos linearmente atē $100 \mathrm{ppm}$ deste antibiātico, devido quizā a um melhor aproveitamento da energia da ração.

- Os resultados obtidos neste estudo evidenciam a ação promotora do crescimento da salinomicina e, embora a conversāo alimentar tenha sido melhorada linearmente, pode se estabelecer em 50 ppm como o nivel mais adequado para : 1eitöes em recria. 


\section{REFERẼNCIAS BIBLIOGRAFICAS}

ALLEN, R.S. Protein metabolism. In: SWENSON, M.J., ed. Duckey's physiology of domestics animals. 8.ed-Cornell, University Press, 1970. p.576-94.

ARMSTRONG, J.D. \& SPEARS, J.W. Intravenous administration of ionophores in ruminants; effects on metabolism independent of the rumen. Journal of Animal Science, Champaign, 66: $1807-17,1988$.

ASSOCIATION OF OFFICIAL AGRICULTURAL CHEMISTS. Official methods of analysis. 10.ed. Washington, AOAC, 1965.

AVICULTURA INDUSTRIAL.. Coxistac versus Narasin: efeito anticoccídico e performance das aves. In: GESSULLI, ed, 1988 . p. $42-45$.

BAGLEY, C.P.; FEAZEL, J.I.; MORRISON, D.G.; LUCAS, D.M. Effects of salinomycin on ruminal characteristics and performance of grazing beef steers. Journal of Animal Science, Champaign, 66: 792-7, 1988,

BALDWIN, R.L. \& ALLISON, M.J. Rumen metabolism. Journal of Animal Science, Champaign; 57: 461-77, 1983.

BANE, D.P.; BEVILL, R.F.; HALL, W.F. Effects of salinomycin on sow weight change during lactation and on sow reproductive performance. Journat of Animat Science, Champaign, 66: $3094-3100,1988$. 
BARBER, R.S.; BRAUDE, R.; HOSKING, Z.D.; MITCHELL, K.G. 01aquindox as performance - promoting feed additive for growing pigs. Animal Feed Science and Technology, 4: 117-23, 1979 .

-BARCLAY, R.A.; FAULKNER, D.B.; FAHEY, G.C. Jr; CMARIK, G.F. Effects of salinomicyn on performance characteristics and apparent dry matter digestion by grazing beef steers. $\mathrm{Nu}-$ trition Reports: International, 33: 43-54, 1986.

BARTLEY, E.E.;HEROD, E.L.; BEETLE, R.M.; SAPIENZA, D. A.; BRENT, B.E.; DAVIDOVICH, A. Effect of monensin or lasalocid, with and without niacin or amicloral on rumen fermentation and feed efficiency. Journal of Animal Science, Champaign, 49: 1006- , 1979.

BERGEN, W.G. \& BATES, . Ionophores; their effect on production efficiency and mode of action. Journal of Anima 1 Science, Champaign, 58: 1465-83, 1984.

BERTO, D.A. Levedura seca de destitaria de ālcool de canade-açücar (Saccharomyces spp.) na alimentação de leitões em recria. Piracicaba, 1985. 133p. (Mestrado - Escola Superior de Agricultura "Luiz de Queiroz"/USP).

BLAIR, R - \& SHIRES, A. Comparison of salinomycin and carbadox as growth promoters for weanling pigs. Canadjan Jour nal of Animal Science, Ottawa, 61: 961-4, 1981.

BOHME, H. \& OSLAGE, H.J. Untersuchungen uber die wirksamkeit von Salinomycin - Natrium als wachstumsforderer in der Schweinemast; experiments on the efficacy of SalinomycinSodium as growth promoter for growing-finishing pigs). Landwirtsch. Forschung., Weiheim, 39: 48-60, 1986. 
BRAUDE, R.; COATES, M.E.; DAVIS, M.K.; HARRISON, G.F.; MITCHELL, K.G. The effect of aureomycin on the gut of the pig. British Journal of Nutrition, Cambridge, 9: 363 , 1955.

CAMPBELL, R.G. The effects of carbadox on the perfomance and carcass characteristics of early-weaned pigs given highand low - protein diets. Animal Production, Edinburg, 34: $111-4,1982$.

CHAPPEL, L.R. \& BABCOCK, W.E. Field trials comparing salinomycin (Coxistac), Monensin, and Lasalocid in the control of coccidiosis in Broilers. Poultry Science, Champaign, 58: 304-7, 1979.

COFFEY, M.T.; CAMPBELL, D.R.; COMBS, G.E. Effects of carbadox (antibiotic) supplementation of weanling swine diets varying in protein and (or) Tysine on performance to market weight. Nutrition Reports International, Slaneham, 32: $959-66,1985$.

CRAVENS, W.W. \&.L. HOLCK. Economic benefics to the Tivestock producer and to the consumer from the use of feed additives. Journal Animal Science, Albany, 31: 1102-1106, 1970 .

CROMWELL, G.L. \& STAHLY, T.S. Efficacy of tiamulin as a growth promotant for growing swine. Journal of Animal Science, Champaign, 60. 14-9, 1985.

CROMWELL, G.L.; STAHLY, T.S.; SPEER, Y.C.; O'KELLY, R. 0. Efficacy of nosiheptide as a growth promotant for growing finishing swine - a cooperative study. Journal of Animal Science, Champaign, 59: 1125-8, 1984. 
DANFORTH, H.D.; RUFF, M.D.; REID, W.M.; JOHNSON, J. Anti coccidial activity of salinomycin in floor-pen experiments with Broilers. Poultry Science, Champaign, 56: $933-8$, $1977 \mathrm{a}$.

DANFORTH, H.D.; RUFF, M.D.; REID, W.M.; MILLER, R.L. Anticoccidial activity of salinomicyn in battery raised broi ler chickens. Poultry Science, Champaign, 56: $926-32$, $1977 \mathrm{~b}$.

DELFINO, J.; MATHISON, G.W.; SMITH, M.W. Effect of lasairid on feedtot performance and energy partitioning in cattie: Journal of Animal Science, Champaign, 66: 136-50, 1988.

DINIUS, D.A.; SIMPSON, M.E.; MARSH, P.B. Effect of monensin fed with forage on digestion and the ruminal ecosystem of steers. Journal of Animal Science, Champaign, 42: 229 , 1976.

EGGUM, B.0.;.THORBECK, G.; BEAMES, R.M.; CHWALIBOG, A.; HENCKEL, S. Influence of diet and microbial activity in the digestive tract on digestibility, and nitrogen and energy metabolism in rats and pigs. British Journal of Nutrition, Cambridge, 48: 161-75, 1982.

ELSASSER, T.H. Potential interactions of ionophore drugs with divalent cations and their function in the animal body. Journal of Animal Science, Champaign, $59:-845=53$, 1984.

ETHERIDGE, R.D.; R.W. SEERLEY; WYATT, R.D. The effect of diet on performance, digestibility, blood composition and intestinal microflora of weaned pigs. Journal of Animal Science, Champaign, 58: 1396-402, 1984. 
FONTENOT, J.P.; WEEB, K.W.; LUCAS, D.M. Effect of salinomycin on in vitro ruminal volatile fatty acids. Journal of Animal Science, Champaign, 51(suppl. 1): $360,1980$. (Abstract).

GILLESPIE, J.R.; GARD, D.I.; GUNERATNE, J.R.; TONKINSON, L. V.; SCHNEIDER, J.H. Comparative floorpen testing of nara. sin and salinomycin in four countries. Poultry science, (supp1.) 65: 170, 1986 (Abstract).

HALE, O.M:; G.L. NEWTON; HAYDON, K.D. Effects of diet and exercise on performance, carcass traits and plasma compo nents of growing - finishing, barrows. Journal of Animal Science, Champaign, 62: 665-71, 1986.

HALVORSON, D.A.; VAN DIJK, C.; BROWN, P. Ionophore toxicjty in turkey breeders. Avian oiseases, Kennet square, 26: $634-9,1983$.

HAMMANT, $C$. Salinomycin found beneficial to birds fed diets low in sulfur amino acid content. Feedstuffs, Minnetonka, 8, 1985 .

HARMS, R.H. \& BURESH, R.E. Influence of salinomycin on the performance of broiler chicks. Poultry Science, Champaign, 66: $51-4,1987$.

HARPER, A.F.; KORNEGAY, E.T.; BRYANT, K.L.; THOMAS, H.R. Efficacy of virginiamycin and a commercially-available lactobacillus probiotic in swine diets. Animal Feed Science and Technology, Amsterdam, 8: 69-76,.. 1983. 
HOLZGRAEFE, D.P.; FAHEY Jr., G.C.; JENSEN, A.H. Influence of dietary alfalfa: orchardgrass hay and lasalocid on in vitro estimates of dry matter digestibility and volatile fatty acid concentrations of cecal contents and rate of digesta passage in sows. Journal of Animal Science, Cham paign, 60: 1235-46, 1985a.

HOLZGRAEFE, D.P.; FAHEY Jr., G.C.; JENSEN, A.H.; BERGER, LL. Effects of fietary alfalfa: orchardgrass hay and lasalocid on nutrient utilization by gravid sows. Journal of Animat-Science, Champaign, 60: 1247-59, 1985b.

KENNELLY, J.J. \& AHERNE, F.X. The effect of fiber in diets formulated to contain different levels of energy and protein on digestibility coefficients in swine. Canadian Journal of Animal Science, Ottawa, 60: 717-26, 1980.

KIRK, D.J.; GREENE, L.W.; SCHELLING, G.T.; BYERS, F.M. EFfects of monensin on monovalent ion metabolism and tissue concentrations in 7 ambs. Journal of Animal Science, Cham paign, 60: 1479-84, 1985a.

KIRK, D.J.; GREENE, L.W.; SCHELLING, G.T.; BYERS, F.M. Effects of monensin on $\mathrm{Mg}, \mathrm{Ca}, \mathrm{P}$ and $\mathrm{Zn}$ metabolism and tissue concentrations in lambs. Journal of Animal Science, Champaign, 60: 1485-90, 1985b.

LANGLOIS, B.E.; CROMWELL, G.L.; HAYS, V.W. Influence of type of antibiotic and lenght of antibiotic feeding period on performance and persistence of antibiotic resistant enteric bacteria in growing-finishing swine. Journal of Animal Science, Champaign, 46: 1383-96, 1978. 
LEESON, S.; HACKER, R.H.; WEY, D. Efficacy of salinomycin as a growth promoter for growing-finishing. swine. Canadian Journal of Animal Science, Ottawa, 61: 1063-5; 1981.

LEMENAGER, R.P.; OWENS, F.N.; LUSBY, K.S.; TOTUSEK, R. Monen sin, forage intake and lactation of range beef cows - Journa 1 of Animal Science, Champaign, 47: 247-54, 1978a.

LEMENAGER, R.P.; OWENS, F.M.; SHOCKEY, B.U.; LUSBY, K.S.; TOTUSEK, R. Monensin effects on rumen turnover rate, twenty-four hour VFA pattern, nitrogen components and cellulose disappearance. Journal of Animal Science, Cham paign, 47: 255-61, 1978b.

LINDEMANN, M.D.; KORNEGAY, E.T.; STAHLY, T.S.; CROMWELL, G.L;; EASTER, R.A.; KERR, B.J.; LUCAS, D.M. The efficacy of salinomycin as a growth promotant for swine from 7 to 97 $\mathrm{kg}$. Journal of Animal Science, Champaing, 6l: 782-8, 1985.

LILLIE, R.J.; L.T. FROBISH; N.C. STEELE; G. GRABER. Effect of dietary copper and tylosin and subsequent withdrawal on growth, hematology and tissue residues on growing - finis hing pigs. Journal of Animal Science, Albany, 45: 100$107,1977$.

MCCLURE, W.H.; FONTENOT, J.P.; WEBB, K.E.; LUCAS, D.M. Feedlot performance of cattle fed different salinomycin. levels. Journal of Animal Science, Champaign, 51 (supp. 1): 380,1980 (Abstract).

MERCHEN, N.R. \& BERGER, L.L. Effect of salinomycin level on nutrient digestibility and ruminal characteristics of sheep and feedlat performance of cattle. Journal of Animal Science, Champaign, 60: 1338-46, 1985. 
MILLER, E.R.; ULREY , D.E.; ACKRERMAN, I .; SCHMIDT, D.A.; HOEFER, H.A.; LUECKE, R.W. Swine hematology from birth to maturity. I. Serum proteins. Journat of Animal Science, Champaign, 20: $31-5,1261$.

MIYADA, V.S. A levedura seca na alimentação de suínos: estudos adicionais sobre o seu valor proteico e vitaminico. Piracicaba, 1987. 159p. (Livre-Docencia - Escola Superior de Agricultura "Luiz de Queiroz"/USP).

MOORE, P.R.; EVENSON-A.;-LUCKEY, T.D.; MCCOY, E.; ELVEHJEN, C.A.; HART, E.B. Use of sulfasuxidine, streptothricin and streptomycin in nutritional studies with the chick. Journal of Biological Chemical, Bethesda, 16: 437, 1946.

MOQRE, R.J.; KORNEGAY, E.T.; LINDEMANN, M.D. Effect of salinomycin in nutrient absorption and retention by growing pigs fed corn-soybean meal diets with or without oat hults or wheat bran. Canadian Journal of Animal Science, Ottawa, 66: 257-65, 1286a.

MOORE, R.J.; KORNEGAY, E.T.; LINDEMANN, M.D. Effect of dietary oat hulis or wheat bran on mineral utilization in growing pigs fed diets with or without saijnomycin. Canadian Journal of Animal Science, Ottawa, 66:267-76, 1986b.

MOORE, R.J.; KORNEGAY, E.T.; GRAYSON, R.L.; LINDEMANN, M. D. Growth, nutrient utilization and intestinal morphology of pigs fed high-fiber diets. Journal of Animal Science, Vir ginia, 66: 1570-72, 1288 .

NAGARAJA, T.G.; DENNIS, S.M.; GALITZER, S.J.; HARMON, D. L. Effect of lasalocid, monensin and thipeptin on lactate production from in vitro rumen fermentation of starch. Canadian Journat of Animal science, Ottawa, 66: 129-39, 1986 . 
O'CONNOR, J.J..; BAUGHN, C.0.; PILOTE, R.R.; ALPAUGH, W.C.; LINKENHEIMER, W.R.; MAPLESDEN, D.C. Tiamulin in the feed for the prevention of swine dysentery and growth promotion of growing pigs. Journal of Animal science, Champaign. 49: $933-38,1979$.

PACHECO, C.R.V.M. Efeitos de oxitetraciclina, sulfametazina e tilosina na performance de suinos em crescimento e acabamento. Piracicaba,. 1978. 99p. (Mestrado - Escola Superior de Agricuitura. "Luiz de Queiroz"/USP).

PENDLUM, L.C.; BOLING, J.A.; BRADLEY, N..W. Levels of monensin with and without tylosin for growing - finishinis steers. Journal of Animal Science, Champaign, 47: 1-5, 1978.

POND, W.G. \& MANER, J.H. Swine production in temperature and tropical environments. San Francisco, W.H. Freeman: 1974. $645 \mathrm{p}$.

POND, W.G. \& YEN, J.T. Effect of suplemental carbadox, an antibiotic combination, or clinoptilolite on weight gain and organ weights of growing swine fed maize or rye as the grain sources. Nutrition Reports International, Stoneham, 35: 801-9, 1987.

POTTER, L.M.; BLAKE, J.P.; BLAIR, M.E.; BLISS, B.A.; DENBOW, D.M. Salinomycin toxicity in turkeys. Poultry Science, Champaign, 65: $1955 \cdots 9,1986$.

PRANGE, R.W.; DAVIS, C.L.; CLARK, J.G. Propionate production in the rumen of holstein steers fed either a control or monensin supplemented diet: Journal of Animal Science, Champaign, $45: 1120-4,1978$. 
PUCHAL, F.; HAYS, V.W.; SPEER, V.C.; JONES, J.D.; CATRON, D. $\checkmark$. The free blood plasma aminoacids of swine as related to the source of dietary proteins. Journal of Nutrition, Bethesda, 85: 11-16, 1962.

RAVINDRAN,..$;$ KORNEGAY, E.T.; WEBB Jr., K.E. Effects of fiber and virginiamycin on nutrient absorption, nutrient retention and rate of passage in growing swine. Journal of Anima 1 Science, Champaign, 59:400-8, 1984.

RIBEIRO de LIMA, F.; STAHLY, T.S.; CROMWELL, G.L. Effects of copper, with and without ferrous sulfide: and antibiotics on the performance of pigs. Journal of Animal Science. Champaign, 52: $241-7,1981$.

RIEDEL, B.B.; BARBER, C.W.; HAYS, T.A.S. The anthelmintic ac tivity of quaternary ammonium compounds in chickens infected with Ascardia galli. Poultry Science, Champaing, 28: 830,1949 .

RILEY Jr., W.W.; ESTEVE-QARCIA, E.; AUSTIC, R.E. Intestina1 absorption of glucose and aminoacids in chickens administered monensin. Poultry Science, Champaign, 65: 22928,1986 .

ROSTAGNO, H.S.; SILVA, D.J.; COSTA, P.M.A.; FONSECA, J.8.; SOARES, P.R.; PEREIRA, J.A.A.; SILVA, M.A. Composiçäo de alimentos e exigencias nutricionais de aves e suinos; tabelas brasileiras. Viçosa, U.F.V., 1983. 59p.

RUSSELL, J.B. A proposed mechanism of monensin action in inhibiting ruminal bacterial growth: effects on ion flux and protonmotive force. Journal of Animal Science, Cham paign, 64: 1519-25, 1987. 
SHIVELY, J.E.; MCMANUS, R.F.; LEESON, S.; HACKER, R.R. Salinomycin for growing-finishing swine. Journal of Animal Science, Champaign, 53(supp 1): 298, 1982a.

SHIVELY, J.E.; MUNIZ, R.A.; ROBINSON, M. Salinomycin for growing-finishing swine. Journal of Animal Science, Cham paign, 53: $\underline{7}, 1982 b$.

SPROTT, L.R.; GOEHRING, T.B.; BEVERLY, J.R.; CORAH, C.R. Effects on ionophores on cow herd production; a review. Journat of Animal Science, Champaign, 66: 1340-6, 1988.

STAHLY, T.S.; CROMWELL, G.L.; MONEGUE, H.J. Effects of the dietary inclusion of copper and (or) antibiotics on the performance ov weanling pigs. Journal of Animal Science, Champaign, 51: 1347-51,. 1980.

STEEL, R.G.S. \& TORRIE, J.H. Principles and procedures of statistics; a biometrical approach. 2.ed. New York, McGraw-Hi17 Book Company, 1980. 664p.

STOKSTAD, E.L.R.; JUKES, T.H.; WILLIAMS, W.L. The growth promoting effect of aureomycin on various types of diets. Poultry Science, Champaign, 32: 1054, 1953.

SWENSON, M.J. Physiology properties, cellular and chemical constituents of blood. In: SWENSON, M.J., ed. Ducke's physiology of domestics animals. 8.ed. Cornell University Press, 1977. p.21-61.

TONKINSON, L.V.; JEFFERS, T.K.; CALLENDER, M.E. Comparative anticoccidial efficacy of narasin and monensin in battery cage trials. Poultry Science (suppl): 62: 1556, 1982. (Abstract). 
VAREL, V.H.; POND; W.G.; YEN, J.T. Influence of dietary fiber on the performance and cellulase activity of growing finishing swine. Journal of Animal Science, Cambridge, 59: $388-99,1984$.

VELQSQ, J.A.F.; MOREIRA, M.J.; SAMPAIO, I.B.M. Efeito da lincomicina como estimulante de crescimento de suinos. Arq. Esc. Vet. UFMG, Belo Horizonte, 34: 345-52, 1982.

VERVAEKE, I.J.; DECUYPERE, J.A.; DIERICK, N.A.; HENDERICKX,H. K. Quantitative in vitro evaluation of the energy metabolism influenced by virginiamycin and spiramycin used as growth promoters in pig nutrition. Journal of Animal Science, Champaign, 49: 846-56, 1979 .

VISEK, W.J. The mode of growth promotion by antibiotics. Journat of Animal Science, Champaign, 46: 1447-69, 1978.

MEBB Jr., K.E.; FONTENOT, J.P.; LUCAS, D.M. Metabolism studies in steers fed different levels of salinomycin. Journal of Animal Science, Champaign, 51 (supp1.): 407, 1980.

WILDE, R.Q. de. Comparison of virginiamycin and salinomycin as growth promoters in growing fattening pigs. Nutrition Abstracts and Reviews, Serie B, Livestock Feeds and Feeding, Wallingford, 54: 367-8, 1984 (Abstract)..

WHEELHOUSE, R.K. \& GROVES, B.I. Salinomycin for growing finisting Barrows and gitts. Canadian Journal of Animal Science, ottawa, 65: 259-263, 1985. 
WHEELHOUSE, R.K.; GRQVES, B.T.; HAMMANT, C.A. Effects of salinomycin and lincomycin upon performance, mortality and intestinal lesion score in broiler chickens using as infeed coccidia model. Canadian Journal of Animal Science, Qttawa, 65: 255-8, 1985.

WORDU, G.; DEBARTHE, J.V.; ERDMAN, R.A.; SHIVELY, J.E. Effect of salinomycin on cecal VFA, digestibility, and rate of passage of digesta in growing pigs. Journal of Animal Science, Champaign, 303, 1985 (Abstract).

WORNICK, R.C.; HINTZE Jr., J.F.; PARADA, J.A.; PINEDO, C.D.; CASTRQ, J.A.; GOMEZ, G.S.; GONZALES, M.J. Resultados de um programa de testes de campo com salinomicina em frangos de corte, durante seis anos, na Amërica Latina. In: Congresso Latino-Americano de Avicultura, Camboriū, S.C., Brasi1. Qutubro, 1983. p.5-17.

YEN, J.T. \& VEUM, T.L. Effect of lysine, tryptophan and(or) carbadox additions to low protein corn-soybean meal diets for young pigs. Journal of Animal Science, Champaign, 55: 1982 .

YYORE, P.; RAYNAUD, J.P.;: CONAN, L.; NACIRI, M. Evaluation of the efficacy of salinomycin in the control of coccidiosis in chicks. Poultry Science, Champaign, 59: 2412-6, 1980 .

ZONTA, E.P. SANEST; sistema de análise estatistica. Peiotas, Universidade Federal de Pelotas, 1983. 
51.

A $\underline{P} \underline{E} \underline{N} \underline{\mathbb{I}} \underline{\mathrm{C}} \underline{\mathrm{E}}$ 
Tabela Al. Peso médio inicial (PMI, $\mathrm{kg}$ ), peso médio final (PMF, $\mathrm{kg}$ ), consumo diärio de ração (CDR, $\mathrm{kg})$, ganho diário de peso $(\mathrm{GDP}, \mathrm{kg})$ e conversão alimentar (CA) dos animais.

Tratamento Blocos PMI, $\mathrm{kg} \quad \mathrm{PMF}, \mathrm{kg} \quad$ CDR, $\mathrm{kf} \quad \mathrm{GDP}, \mathrm{kg} \quad \mathrm{CA}$

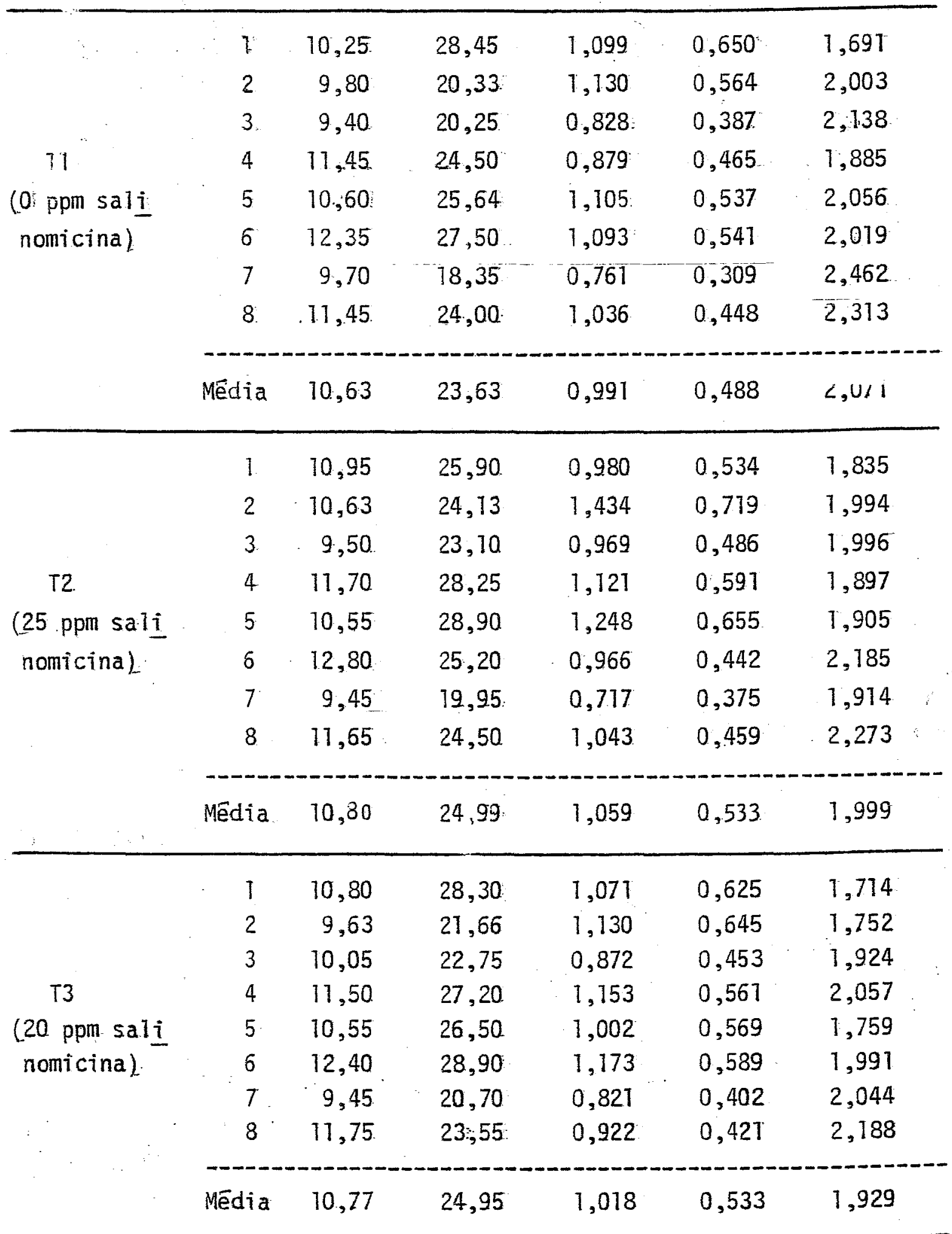


Tabela A2. Continuação.

\begin{tabular}{|c|c|c|c|c|c|c|c|c|c|}
\hline $\begin{array}{l}\text { Trata- } \\
\text { mento }\end{array}$ & Blocos & $\begin{array}{l}\text { Hemato- } \\
\text { crito, }\end{array}$ & $\begin{array}{r}\text { Hemoglo } \\
\% \text { bina, g/dT }\end{array}$ & $\begin{array}{l}\text { Urēia } \\
\mathrm{mg} / \mathrm{d} \mathrm{l}\end{array}$ & $\begin{array}{c}\text { Proteina } \\
\text { total } \\
\mathrm{g} / \mathrm{d} \text { i }\end{array}$ & $\begin{array}{c}\text { Albumina } \\
\text { g/dl }\end{array}$ & $\begin{array}{c}\text { Globulina } \\
\text { g/d? }\end{array}$ & $\begin{array}{l}\text { Relação } \\
\text { Alb/Glob. }\end{array}$ & $\begin{array}{l}\text { Trigli- } \\
\text { cerid os } \\
\mathrm{mg} / \mathrm{d} \text {. }\end{array}$ \\
\hline \multirow[t]{2}{*}{$\begin{array}{l}\mathrm{T4} \\
\text { (75 ppm } \\
\text { salino- } \\
\text { micina) }\end{array}$} & $\begin{array}{r}1 \\
2 \\
3 \\
4 \\
5 \\
6 \\
7 \\
8\end{array}$ & $\begin{array}{l}35,5 \\
32,0 \\
36,5 \\
27,5 \\
34,5 \\
35,0 \\
32,0 \\
38,0\end{array}$ & $\begin{array}{r}10,95 \\
9,87 \\
11,55 \\
8,50 \\
11,20 \\
11,25 \\
10,50 \\
13,05\end{array}$ & $\begin{array}{l}33,0 \\
24,0 \\
17,0 \\
32,0 \\
30,0 \\
28,0 \\
39,0 \\
24,0\end{array}$ & $\begin{array}{l}5,4 \\
5,1 \\
5,3 \\
6,2 \\
6,3 \\
6,0 \\
7,2 \\
5,8\end{array}$ & $\begin{array}{l}3,1 \\
3,0 \\
3,0 \\
3,4 \\
3,8 \\
3,4 \\
2,9 \\
2 ; 9\end{array}$ & $\begin{array}{l}2,3 \\
2,1 \\
2,3 \\
2,8 \\
2,5 \\
2,6 \\
4,3 \\
2,9\end{array}$ & $\begin{array}{l}1,35 \\
1,43 \\
1,30 \\
1,21 \\
1,52 \\
1,31 \\
0,67 \\
1,00\end{array}$ & $\begin{array}{l}40,0 \\
46,0 \\
70,0 \\
62,0 \\
50,0 \\
43,0 \\
78,0 \\
87,0\end{array}$ \\
\hline & Mëdia & 33,87 & 10,85 & 28,37 & 5,9 & 3,1 & 2,72 & 1,22 & 59,5 \\
\hline \multirow[t]{2}{*}{$\begin{array}{l}\text { T5 } \\
\text { (100 ppm } \\
\text { salino- } \\
\text { micina) }\end{array}$} & $\begin{array}{l}1 \\
2 \\
3 \\
4 \\
5 \\
6 \\
7 \\
8\end{array}$ & $\begin{array}{l}36,0 \\
31,0 \\
34,0 \\
28,0 \\
35,5 \\
30,5 \\
34,5 \\
34,0\end{array}$ & $\begin{array}{r}11,30 \\
9,30 \\
10,80 \\
9,30 \\
11,85 \\
9,85 \\
11,25 \\
11,55\end{array}$ & $\begin{array}{l}26,0 \\
29,0 \\
18,0 \\
34,0 \\
25,0 \\
24,0 \\
30,0 \\
33,0\end{array}$ & $\begin{array}{l}5,4 \\
5,0 \\
5,7 \\
6,3 \\
6,7 \\
5,7 \\
6,5 \\
5,2\end{array}$ & $\begin{array}{l}3,5 \\
3,0 \\
3,0 \\
3,0 \\
3,4 \\
2,8 \\
3,5 \\
3,1\end{array}$ & $\begin{array}{l}1,9 \\
2,0 \\
2,7 \\
3,3 \\
2,7 \\
2,9 \\
3,0 \\
2,1\end{array}$ & $\begin{array}{l}1,84 \\
1,50 \\
1,11 \\
0,91 \\
1,26 \\
0,97 . \\
1,17 \\
1,48\end{array}$ & $\begin{array}{l}45,0 \\
48,0 \\
50,0 \\
55,0 \\
47,0 \\
40,0 \\
70,0 \\
48,0\end{array}$ \\
\hline & Mëdia & 32,93 & 10,65 & 27,37 & 5,73 & 3,16 & 2,57 & 1,28 & 50,37 \\
\hline
\end{tabular}

